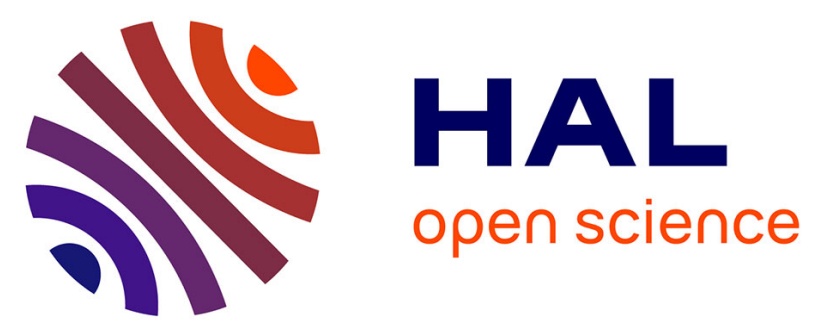

\title{
Plasticity of Plant Form and Function Sustains Productivity and Dominance along Environment and Competition Gradients. A Modeling Experiment with GEMINI
}

Vincent Maire, Jean-Francoise Soussana, Nicolas Gross, Bruno Bachelet, Loic

Pages, Raphaël Martin, Tanja Reinhold, Christian Wirth, David R.C. Hill

\section{To cite this version:}

Vincent Maire, Jean-Francoise Soussana, Nicolas Gross, Bruno Bachelet, Loic Pages, et al.. Plasticity of Plant Form and Function Sustains Productivity and Dominance along Environment and Competition Gradients. A Modeling Experiment with GEMINI. Ecological Modelling, 2013, 254, pp.80-91. 10.1016/j.ecolmodel.2012.03.039 . hal-00706761

\section{HAL Id: hal-00706761 \\ https://hal.science/hal-00706761}

Submitted on 29 May 2020

HAL is a multi-disciplinary open access archive for the deposit and dissemination of scientific research documents, whether they are published or not. The documents may come from teaching and research institutions in France or abroad, or from public or private research centers.
L'archive ouverte pluridisciplinaire HAL, est destinée au dépôt et à la diffusion de documents scientifiques de niveau recherche, publiés ou non, émanant des établissements d'enseignement et de recherche français ou étrangers, des laboratoires publics ou privés. 
1Running title: Plant plasticity modeling experiment

2Title: Plasticity of plant form and function sustains productivity and dominance along 3environment and competition gradients. A modeling experiment with GEMINI.

4Vincent Maire ${ }^{1}$, Jean-François Soussana ${ }^{1}$, Nicolas Gross ${ }^{1 *}$, Bruno Bachelet ${ }^{1 * *}$, Loïc Pagès ${ }^{2}$, 5Raphaël Martin ${ }^{1}$, Tanja Reinhold ${ }^{3}$, Christian Wirth ${ }^{3 * *}$ and David Hill ${ }^{4 * * *}$

6

$7^{1}$ INRA UR874 UREP, Grassland Ecosystem Research, F-63100 Clermont-Ferrand, France 8²INRA UR1115 PSH, Plantes et Systèmes de cultures Horticoles, F-84914 Avignon, France 9³ax-Planck Institute for Biogeochemistry, D-07745 Jena, Germany

104Clermont Université, Université Blaise Pascal, LIMOS, BP 10448, F-63000 Clermont-Ferrand, 11France

12* Current address: CNRS, Centre d'étude Biologique de Chizé, 79360 Beauvoir-Sur-Niort, France

$13^{* *}$ Current address: Clermont Université, Université Blaise Pascal, LIMOS, BP 10448, F-63000 14Clermont-Ferrand, France

$15^{* * *}$ Current address: Universität Leipzig, Institut für Biologie I, 04103 Leipzig, Germany $16^{* * * *}$ Current address: CNRS, UMR 6158, LIMOS, F-63173 Aubière, France 17Authors for correspondence (phone +33 4736244 23; e-mail jfsoussana@clermont.inra.fr,) 18Email addresses: nicolas.gross@cebc.cnrs.fr, david.hill@univ-bpclermont.fr, bachelet@isima.fr, 19rmartin@clermont.inra.fr, cwirth@uni-leipzig.de

20

21Website of GEMiñ project: https://www1.clermont.inra.fr/urep/modeles/gemini.htm 22Figure: 8; Table: 2

23Key-Words: Partitioning, growth, carbon, nitrogen, functional balance, coordination theory, 24biodiversity; grassland community 


\section{ABstract}

26GeminI, a mechanistic model linking plant functional traits, plant populations, community 27dynamics, and ecosystem scale fluxes in grasslands has been reported in a companion paper 28(Soussana et al., 2012). For monocultures and six species mixtures of perennial grass species, 29this model has been successfully evaluated against experimental data of above-ground net 30primary productivity (ANPP) and plant community structure across nitrogen and disturbance 31(cutting frequency) gradients. The Gemins model combines two categories of processes: i) C 32and $\mathrm{N}$ fluxes, ii) morphogenesis and architecture of roots and shoots and demography of 33clonal plant axes. These two process categories constrain the form and function of the 34simulated clonal plants within plastic limits. We show here that the plasticity of the simulated 35plant populations accounts for well-established empirical laws: i) root:shoot ratio, ii) self36thinning, iii) critical shoot $\mathrm{N}$ content, and iv) role of plant traits (specific leaf area and plant 37height) for population response to environmental gradients (nitrogen and disturbance). 38Moreover, we show that model versions for which plasticity simulation has been partly or 39fully suppressed have a reduced ANPP in monocultures and in binary mixtures and do not 40capture anymore productivity and dominance changes across environmental gradients. We 41conclude that, along environmental and competition gradients, the plasticity of plant form and 42function is required to maintain the coordination of multiple resource capture and, hence, to 43sustain productivity and dominance. 


\section{INTRODUCTION}

45The outcome of biotic interactions is a dynamic process which entails 'the explicit inclusion 46of organismal trade-offs, of environmental constraints, and of the basic mechanisms of 47interspecific interactions' (Tilman, 1990) to be predictable. In a companion paper (Soussana 48et al., 2012), we present the Gemini model (Grassland Ecosystem Model with INdividual 49centred Interactions), which couples within a common modeling framework: carbon, nitrogen 50and water cycles (ecosystem scale), plant population dynamics based on resource competition 51(community scale) and physiological and morphological plasticity of clonal plants 52(organismal trade-offs).

53 An individual-centred approach was used to develop this coupling across scales and, 54hence, to develop a dynamical structure-function-diversity model capable of simulating the 55dynamics of plant species within a community as well as the role of traits and their plasticity 56for ecosystem functioning (Soussana et al., 2012; Maire, 2009). GEmINI is an individual57centred model, rather than being individual-based, since it simulates average individuals 58within each plant population. Here we show that the details of physiological, morphological 59and demographic mechanisms allowing plant and population plasticity in the model are both 60necessary and sufficient (according to the parsimony principle) to simulate major trends in 61productivity and dominance across the perennial grass species studied.

62 The individual-based modeling approach offers the possibility to simulate the plastic 63adjustments of plant form and function in response to resource levels mediated by interactions 64with neighbors (Höglind et al., 2001; Yin and Schapendonk, 2004). Such plastic responses are 65shown to be mainly phenotypic (Grassein et al., 2010), species-specific and sometimes 66adaptive when they are correlated positively to changes in plant growth (Useche and Shipley, 672010a, 2010b; Pontes et al., 2010). Competition / facilitation biotic interactions are in part 68determined by these plastic responses of plants to resource levels (Grime, 1973; Tilman, 
691984), which may enhance species coexistence and complementarity in plant communities 70(Soussana and Lafarge, 1998). For instance, Van Ruijven and Berendse (2003) have shown a 71reduction of leaf nitrogen content associated with higher plant nitrogen use efficiency when 72species grew at higher diversity level, enhancing the complementarity of nitrogen use and the 73functioning of grassland community. Therefore, mechanisms underpinning species plasticity 74are a prerequisite to explain species assembly rules in grassland communities and their 75consequences for ecosystem functioning (Grime and Mackey, 2002). Structure-function76diversity models like Gemini can help in understanding the role of plasticity for the adaptation 77of plant populations to environmental gradients across species diversity levels.

78 Phenotypic plasticity is only adaptive if it is properly co-ordinated with environmental 79fluctuation (Sultan, 2004; De Jong, 2005), i.e. when a plant modifies its phenotype by an 80appropriate amount and at a certain speed in order to optimize growth and fitness (Useche et 81al., 2010a). This principle is applied in the Gemini model (see the companion paper, Soussana 82et al., 2012 for full details) through a coordination of above and below-ground resource 83capture that ensures that no resource is in excess (Chapin, 1991) and through the coordination 84of morphogenesis and of assimilate supply. First, physiological plasticity to light and nitrogen 85levels is obtained by combining: i) the functional balance hypothesis (Davidson, 1969; 86Wilson, 1988), which assumes that partitioning of growth between shoots and roots tends to 87balance shoot photosynthesis and root $\mathrm{N}$ acquisition to ensure $\mathrm{C}$ and $\mathrm{N}$ homeostasis; ii) the 88photosynthesis coordination hypothesis (Chen et al., 1993, Maire et al., 2012), which assumes 89that partitioning between shoot structures and photosynthetic proteins maintains a leaf protein 90content co-limiting the dark (Rubisco activity) and light driven (RuBP regeneration) reactions 91of $\mathrm{C}_{3}$ leaf photosynthesis. Second, morphological plasticity is obtained by assuming a 92potential morphogenesis which adjusts the emission, the elongation and the senescence of 93leaves and roots in function of daily temperature and photoperiod and of daily temperature 
94and soil nitrogen concentration, respectively (Lemaire, 1999; Wu et al., 2004). Third, at the 95population scale, daily temperature and PAR (photosynthetically active radiation) fraction at 96the bottom of the canopy determine the plant axis ramification process (Neuteboom and 97Lantinga, 1989; Lafarge et al., 2005). Finally, plant growth is simulated as the minimum 98between supply (assimilate partitioning and reserves remobilization) and demand 99(morphogenesis and ramification) limited growth rates.

100 In this second paper, we focus on the role of physiological, morphological and 101population plasticity for species net primary productivity (an estimator of fitness for clonal 102plants) along resource (nitrogen), disturbance (cutting frequency) and competition (mixtures 103versus monocultures) gradients. We first evaluate the ability of the model to account for well104established empirical laws concerning: i) resource-based adjustments in root / shoot ratio, ii) 105self-thinning, iii) critical shoot $\mathrm{N}$ content, and iv) role of plant traits (specific leaf area and 106plant height) for responses to environmental gradients (nitrogen and disturbance). By 107comparing model versions of different complexity, we then test the following hypothesis: 108plant morphological (root and shoot morphology) and physiological (leaf $\mathrm{N}$ content, leaf 109photosynthesis) plasticity, as well as plant population (axis density) plasticity, are needed for 110maintaining population fitness (i.e. above-ground net primary productivity) across resource, 111disturbance and competition gradients.

\section{Methods}

\subsection{Model purpose}

115The model is described following the ODD (Overview, Design concepts and Details) standard 116protocol proposed by Grimm et al. (2006) for individual-based and agent-based models in 117Soussana et al. (2012). A detailed list of all 132 equations, as well as the 187 variables and the 
118100 default parameter values and their units is available (at 119www1.clermont.inra.fr/urep/modeles/gemini.htm) and will be send on request.

120 The main purpose of Gemini is to understand the dynamics and plasticity of plant species 121within a community and the role of traits and their plasticity for ecosystem functioning. The 122model considers climatic (short-wave radiation, temperature and precipitation) and 123atmospheric $\left(\mathrm{CO}_{2}\right.$ concentration) abiotic drivers. Management conditions concern both 124disturbance (through defoliation) and fertilization (inorganic and organic $\mathrm{N}$ supply). The 125model was built with a modular architecture, which allows the inclusion, or not, of a range of 126biotic agents (plant species, soil microbial decomposers and domestic herbivores) as well as 127environment and management modules (soil, vegetation, fertilization and cutting).

128 Gemins can simulate a potentially unlimited number of plant species (or plant populations 129from the same species) from currently two plant functional types (perennial grasses and 130legumes). The model focuses on the acquisition and the utilization of two major resources 131(light and nitrogen) by plants and their consequences for the carbon and nitrogen cycles.

\subsection{State variables and scales}

134Gemini consists of vegetation, soil and herbivore sub-models, coupled with environment and 135management sub-models (for a full description of the model, see Soussana et al., 2012). The 136vegetation sub-model, named CANOPT is an individual-centred model of a multi-species stand 137comprising clonal grasses and/or legumes and forming a multi-layer plant canopy. Each 138clonal plant population is described as a collection of identical axes (e.g. tillers for grasses). 139Moreover, all plant species are assumed to be perfectly mixed in the horizontal plane. Plant 140population demography is calculated from the vegetative multiplication and mortality of axes. 141Other demographic processes, including flowering, fruiting, dispersion, germination and 142recruitment from seeds are not considered, since these processes are minimized by regular 
143disturbance through cutting and grazing in temperate grasslands dominated by perennial 144clonal pasture species (e.g. Harper, 1978).

145 The vegetation sub-model consists of four modules: i) a biochemical module, which 146simulates the $\mathrm{C}$ and $\mathrm{N}$ balance and the partitioning of growth among shoot structures $\left(W_{\mathrm{s}}\right)$, 147leaf proteins $\left(W_{\mathrm{P}}\right)$ and roots $\left(W_{\mathrm{R}}\right)$ for mean plant axes in each plant population. For each plant 148population, the corresponding state variables are the axes number $\left(\mathrm{D}, \mathrm{m}^{-2}\right)$, and the mass per 149axis of three structural compartments $\left(W_{\mathrm{S}}, W_{\mathrm{P}}\right.$ and $\left.W_{\mathrm{R}}\right)$ and of $\mathrm{C}$ and $\mathrm{N}$ substrates and of two $\mathrm{C}$ 150and two $\mathrm{N}$ reserve compartments; ii) a shoot morphogenesis module, which computes the 151demography and size of leaves (two state variables, length and mass per leaf); iii) a root 152morphogenesis module, which computes the demography and size of roots (two state 153variables, length and mass per root); iv) a competition module which calculates short-wave 154radiation and inorganic $\mathrm{N}$ partitioning among mixed plant populations.

155 The environment sub-model calculates the microclimate within the canopy and the 156inorganic $\mathrm{N}$ balance of the soil (or of the substrate when the vegetation model is not coupled 157to the soil model). The management sub-model schedules events caused by grassland 158management (cutting dates, grazing periods, $\mathrm{N}$ fertilizer applications).

\section{9}

\subsection{Model parameterization and evaluation}

161The experimental site used for model calibration was established in spring 2002 in an upland 162area of central France (Theix, $45^{\circ} 43^{\prime} \mathrm{N}, 03^{\circ} 01^{\prime} \mathrm{E}, 870 \mathrm{~m}$ a.s.l.) on a granitic brown soil 163(Cambisol, FAO). The local climate is semi-continental, with a mean annual temperature of $1649^{\circ} \mathrm{C}$ and a mean annual rainfall of $760 \mathrm{~mm} .13$ native perennial $\mathrm{C}_{3}$ grass species that co-occur 165in mesic permanent grasslands were studied in monocultures: Alopecurus pratensis, 166Anthoxanthum odoratum, Arrhenatherum elatius, Dactylis glomerata, Elytrigia repens, 167Festuca arundinacea, Festuca rubra, Holcus lanatus, Lolium perenne, Phleum pratense, Poa 
168pratensis, Poa trivialis, Trisetum flavescens. A Lolium perenne cultivar ('Clerpin’) was added 169as a control. Henceforth, species are referred to by their species (e.g. A. pratensis) name.

170 The calibration procedure of the model has been reported by Soussana et al., (2012). 171Briefly, out of a total of 100 parameters, 65 have been considered as constant across the grass 172species investigated with a value taken from the literature. The remaining parameters were 173estimated by species from plant trait values measured in a non-limiting nutrient treatment 174(360 kgN ha ${ }^{-1} \mathrm{yr}^{-1} ; 3$ cuts $\left.\mathrm{yr}^{-1}\right)$ of the field experiment comparing 13 grass species grown in 175monocultures (see the calibration of these parameters in Soussana et al., 2012). In this 176treatment, neither nutrients nor water resources were limiting above-ground grass growth 177(Pontes et al., 2007, Maire et al., 2009).

178 Two parameters ( $L L_{\text {plast}}$, the branching order dependency of potential root length and $179 T r$, the thermal time interval between two successive root emission events) were optimized by 180maximizing axis biomass $\left(W_{\mathrm{G}}\right)$. This first optimization was done on $\mathrm{C}-\mathrm{N}+$ management 181treatment using constant axis density for each species. The two population demography 182parameters (intcl, the clonal integration and $T_{s e n}$, the lifespan of an axis) were then 183optimized by fitting simulated to measured tiller density $(D)$ per unit ground area. This second 184optimization was done after the root parameters optimization.

185 Predicted and measured annual dry-matter yields were highly correlated without bias 186across species, $\mathrm{N}$ supply and cutting frequency treatments in monocultures and in mixtures of 187six species (Soussana et al., 2012). The GEminI model could therefore simulate without bias 188responses to nitrogen and disturbance gradients of net primary productivity and of plant 189community structure.

190 


\subsection{Experimental design for testing the model against empirical laws}

194We have tested model patterns against four types of well-established empirical laws: i) 195changes in root:shoot ratio following an abrupt change in resource availability, ii) self196thinning, iii) critical shoot $\mathrm{N}$ content decline during shoot growth, and iv) role of plant traits 197(specific leaf area and plant height) for population response to environmental gradients 198(nitrogen and disturbance). These patterns were studied with monocultures grown under 199constant environmental conditions $\left(T_{\mathrm{a}}=14^{\circ} \mathrm{C}, P P F D=700 \mu \mathrm{mol} \mathrm{m}{ }^{-2} \mathrm{~s}^{-1}\right)$.

200 First, short-term responses of model compartments to disturbance (cutting) and to 201nutrients stress (N deprivation) were tested. Two partitioning functions $P$ and $Q$ control the 202partitioning of dry matter between shoot and root structures and between shoot structures and 203shoot proteins, respectively. $P$ is calculated as the functional balance between shoot $\mathrm{C}$ and 204root N capture rates (Eq. 1, adapted from Hilbert and Reynolds, 1991; see supplementary 205materials SI1 and SI2 in Soussana et al. (2012) for full details). $Q$ is calculated following the 206coordination hypothesis of leaf photosynthesis (Chen et al., 1993; Maire et al., 2009).

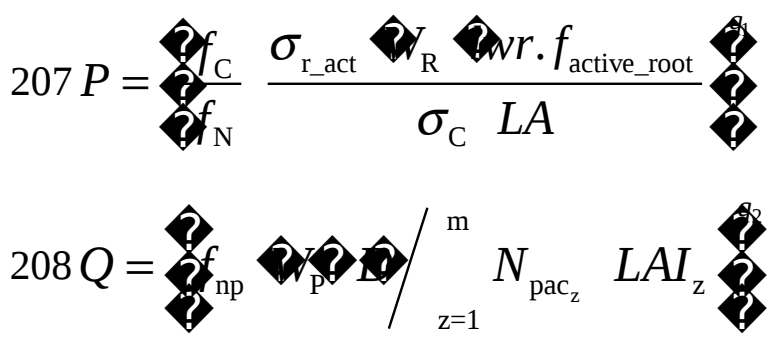

209Where $f_{\mathrm{C}} / f_{\mathrm{N}}$ is the C:N plant ratio, $\sigma_{\mathrm{r}_{-} \text {act }}$ is the root $\mathrm{N}$ uptake rate, $W_{\mathrm{R}}$ is the root dry mass, 210 lwr is the root area to mass ratio, $f_{\text {active_root }}$ is the proportion of active roots, $\sigma_{\mathrm{C}}$ is the net 211photosynthesis rate, $L A$ is the plant axis leaf area, $f_{\mathrm{np}}$ is the $\mathrm{N}$ fraction in shoot proteins, $W_{\mathrm{p}}$ is 212the shoot proteins mass, $D$ is the axis density per unit ground area, $N_{\text {pac }_{z}}$ and $L A I_{\mathrm{z}}$ are the 213coordinated leaf photosynthetic content and the leaf area index in layer $\mathrm{z}$, respectively. Power 214coefficients $q_{1}$ and $q_{2}$ vary the degree of control on partitioning for $P$ and $Q$ variables, 215respectively. 
A critical $\mathrm{N}$ concentration curve is defined as being the minimum plant $\mathrm{N}$ 217concentration allowing maximum growth rate and is related to stand dry matter accumulation 218by a negative power function in a number of $\mathrm{C}_{3}$ species, including perennial forage grasses 219(Lemaire et al., 2008). The ability of the model to simulate critical shoot $\mathrm{N}$ content decline 220during canopy regrowth was tested by simulating $D$. glomerata monocultures grown under 221close to non-limiting nitrogen conditions (corresponding to the $\mathrm{C}-\mathrm{N}+$ experimental treatment). 222 Third, the model's ability to simulate self-thinning (i.e. the negative power law 223relating the individual mass and the density of population units; e.g. Harper, 1978) was tested 224across species in monocultures and for two $\mathrm{N}$ fertilizer supplies $(\mathrm{N}-, \mathrm{N}+)$ at low cutting 225frequency (three cuts per year).

226 Finally, the ability of the model to reproduce species specific responses to disturbance 227and to nitrogen was tested for a range of measured plant functional trait values (SLA, specific 228leaf area and plant height) by using simulated log response ratios (LNRR). Log response 229ratios are the logarithms of the ratios of species performances along an environmental

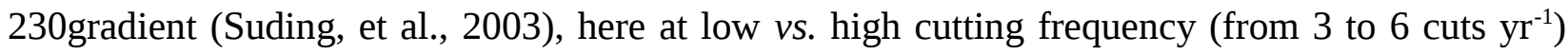
231and at low vs. high $\mathrm{N}$ supply (from 12 to $36 \mathrm{~g} \mathrm{~N} \mathrm{~m}^{-2} \mathrm{yr}^{-1}$ ). A positive LNRR value indicates a 232higher species performance at the higher end of the gradient (i.e. at high cutting frequency and 233at high N). Conversely, a negative value indicates a lower species performance at the lower 234end of the gradient.

\subsection{Testing the role of plant and population plasticity}

237To test the role of plasticity for net primary productivity and its stability along resource and 238disturbance gradients (see Fig. 1 for the conceptual design of the modeling experiment), the 239full Gemini model (FP) was compared with simplified versions offering reduced plasticity 240(from $\mathrm{RP}_{1}$ to $\left.\mathrm{RP}_{4}\right)$ and reduced coordination of growth $\left(\mathrm{RP}_{5}\right.$ and $\left.\mathrm{RP}_{6}\right)$ : 
241- $\mathrm{RP}_{1}$, full model but without axis demography resulting in constant axis density,

242- $\mathrm{RP}_{2}$, same as $\mathrm{RP}_{1}$ but without explicit root morphogenesis,

243- $\mathrm{RP}_{3}$, same as $\mathrm{RP}_{1}$ but without explicit shoot morphogenesis,

244- $\mathrm{RP}_{4}$, same as $\mathrm{RP}_{1}$ but without explicit root and shoot morphogenesis,

245- $\mathrm{RP}_{5}$, same as $\mathrm{RP}_{4}$ but with equal distribution of assimilates to leaf structure and leaf proteins,

246- $\mathrm{RP}_{6}$, same as $\mathrm{RP}_{4}$ but with equal distribution of assimilates to leaf structure and roots.

247 The corresponding modules (i.e. axis demography, root and shoot morphogenesis,

248assimilate partitioning) were inactivated either by setting parameter values to zero, or by 249replacing them by fixed parameter values (Table 1).

250 In order to suppress axis demography in $\mathrm{RP}_{1}$, intcl and $\mathrm{Tsen}_{0}$ parameters were set to zero 251in the ramification module. In $\mathrm{RP}_{2}, \mathrm{RP}_{3}$ and $\mathrm{RP}_{4}$, morphogenesis modules were replaced by 252constant parameter values by species (Fig. 1 ). In $\mathrm{RP}_{2}$ and $\mathrm{RP}_{4}$, root morphogenesis was 253replaced by two species-specific parameters: a constant area to mass ratio of roots (lwr) and a 254constant root senescence rate (TRootsen $)$. In $\mathrm{RP}_{3}$ and $\mathrm{RP}_{4}$, shoot morphogenesis was replaced 255by a constant leaf area ratio ( $L A R$, leaf area to plant mass ratio) and by a constant shoot 256senescence rate $\left(\right.$ TShoot $\left._{\mathrm{Sen}}\right)$. In addition, the shoot architecture module was replaced by a 257constant plant canopy density (leaf area per unit canopy volume, $C_{\mathrm{H}}$ ) and by a constant leaf 258angle (theta) (Table 1). In $\mathrm{RP}_{5}$ and $\mathrm{RP}_{6}$, fixed and equal assimilate fractions to leaf structure 259and leaf proteins $\left(\mathrm{RP}_{5}\right)$ and to leaf structure and roots $\left(\mathrm{RP}_{6}\right)$ were obtained by setting the value 260of $q_{2}$ and $q_{1}$ parameter to zero in Eq. 2 and 1, respectively.

261 The optimization procedure used for the full plasticity version (FP) was then applied to 262each reduced plasticity model version. In the reduced plasticity version $\mathrm{RP}_{1}$, the two root 263parameters $L L_{\text {plast }}$ (branching order dependency of potential root length) and $\operatorname{Tr}$ (thermal time 264interval between two successive root emission events) were optimized as in FP version. 
265Values of these parameters were calculated for each species using the outputs of previous 266equilibrium simulations for the $\mathrm{C}-\mathrm{N}+$ treatment (Table 1B).

267 Reduced and full plasticity model versions were first compared for monocultures. Three 268grass species, which are representative of three plant $\mathrm{N}$ strategies (Maire et al., 2009), were 269used: A. odoratum (short and exploitative grass), A. elatius (tall and exploitative grass), and 270F. arundinacea (tall and conservative grass). Then, in order to test the role of plasticity for the 271outcome of plant-plant interactions, model versions with full and reduced plasticity were 272compared with binary mixtures. Finally, simulated species and model versions were compared 273along resource and disturbance gradients: (i) a light gradient with 100, 80 and $60 \%$ of the 274daily short-wave radiation (PPFD) of the experimental site; (ii) a nitrogen gradient 275contrasting fertilization supply rates of 360, 120 and $60 \mathrm{kgN} \mathrm{ha}^{-1} \mathrm{yr}^{-1}$; (iii) a disturbance

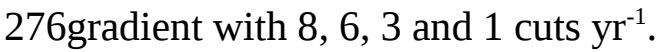

277 Simulations were run for 10 years with the experimental site climate (years 2003-2004 in 278loop for which data were available, see Pontes et al., 2007) and management conditions. Spin279up runs and a restart procedure allowed initializing plant populations close to steady-state. 280Simulations were stopped for a given plant population whenever the substrate $\mathrm{C}$ mass tended 281towards zero (i.e. population death) or increased above an unrealistic value (greater than the 282plant structural C mass). Means were calculated over the simulation period of the plant 283population. With the FP model version simulations lasted in monocultures and mixtures 3655 284and 3000 days, on average. With the $\mathrm{RP}_{1}$ model version simulations lasted in monocultures 285and mixtures 2237 and 1715 days, on average. Within three species mixtures, the average 286duration of coexistence between two simulated species reached 473 days. Therefore, some of 287the simulations lasted for a shorter time period than 10 years. 


\subsection{Data analysis}

291An analysis of variance and Tukey's post-ANOVA comparisons at a p-level of 5\% were used 292to analyze simulated above-ground net primary productivity (ANPP) across species, plasticity 293levels and environmental gradients in both monocultures and mixtures. Moreover, these tests 294were also applied to model outputs indicating light and nitrogen capture: the absorbed fraction 295of photosynthetically active radiation (FAPAR) and the nitrogen uptake rate per unit root area 296(Su). All statistical tests were performed with the software - Statgraphics Plus (Manugistics, 297Rockville, MD, USA).

298

\section{Results}

\subsection{Simulating co-limitation of growth by light and inorganic $\mathbf{N}$ capture}

301After a cut, the $P$ partitioning variable peaks at a high value thereby increasing partitioning to 302shoot structures at the expense of partitioning to root structures. During shoot regrowth after 303cutting, the gradual increase in photosynthesis leads to an exponential decline in $P$ which 304tends asymptotically to one (Fig. 2A). This indicates the reestablishment of a functional 305balance between roots and shoots. Cutting also induces a sharp drop in the second partitioning 306variable $(Q)$ as the residual leaf area becomes exposed to full radiation. This increases the leaf 307N content required for photosynthetic coordination, leading to an increased partitioning to leaf 308photosynthetic proteins at the expense of leaf structures. During shoot regrowth, 309photosynthetic proteins replenishment increases asymptotically $Q$ value towards one and leaf 310photosynthesis coordination is re-established. Within one month after a cut, as $P$ and $Q$ values 311both converge towards one, growth is again co-limited by nitrogen, light and $\mathrm{CO}_{2}$ capture.

312 In the same way, after nitrogen deprivation a reduced root inorganic $\mathrm{N}$ uptake leads to a 313decline in $P$ value (Fig. 2B) and, thereby, to a preferential partitioning of assimilates to roots 314compared to shoot structures. Both increased root growth and a de-repression of root $\mathrm{N}$ uptake 
315capacity (Soussana et al., 2012) lead to a restoration of $\mathrm{N}$ uptake and to an asymptotic 316increase of $P$ value towards one. $Q$ is little affected by inorganic $N$ deprivation (Fig. 2B) and 317its value stays close to one. Hence, by adjusting their root:shoot ratio and their $\mathrm{N}$ uptake 318capacity, $\mathrm{N}$ deprived plants tend towards a co-limitation of growth by nitrogen uptake and by 319photosynthesis. P and Q values show oscillations over a few days (Fig. 2). Such oscillations 320are caused by the emission and senescence of individual leaves and roots, which alters 321root:shoot functional balance through small changes in leaf and root area.

\subsection{Critical shoot nitrogen content decline}

324Critical shoot N content (see Methods) declines with above-ground biomass (Lemaire et al., 3252008) according to a power law. This empirical law was tested with Dactylis glomerata under 326close to non-limiting nitrogen conditions (corresponding to the $\mathrm{C}-\mathrm{N}+$ experimental treatment). 327During the first part of the regrowth, simulated shoot $\mathrm{N}$ concentration fits to the empirical law 328(Fig. 3), showing that this law may therefore be a consequence of coordinated plant growth. 329However, above a leaf area index of 5 simulated changes in shoot $\mathrm{N}$ content slightly 330underestimate the empirically established critical nitrogen decline curve.

\subsection{Simulating size vs. density relationships}

333Between species variations in mean individual shoot mass $\left(W_{\mathrm{s}}+W_{\mathrm{P}}\right)$ and mean density $(D)$ of 334plant axes were negatively correlated according to a power law (exponent -0.94, Fig. 4A). 335Data obtained in spring in the field experiment (Maire, 2009) showed a similar exponent (3361.12) between mean shoot tiller mass and tiller density (Fig. 4B). Simulations of size vs. 337density relationships with both shoots and roots (Fig. 4A, $W_{\mathrm{G}}$ ) indicated a lower exponent in 338absolute value (close to $-3 / 4$ ) of the size vs. density relationship. Therefore, the model captures 339an essential property of plant canopies that relates the size and density of a plant population. 
3403.4. Predicted productivity vs. traits relationships.

341The simulated log-response ratio (LNRR) of above-ground net primary productivity (ANPP) 342to cutting frequency is significantly and positively correlated with $S L A\left(r^{2}=0.59, p<0.01\right.$, 343Fig. 5A). This indicates that the higher the SLA of the species, the higher its biomass at high 344compared to low cutting frequency. In the same way, the LNRR of ANPP to $\mathrm{N}$ supply is 345significantly and negatively correlated with plant height $\left(r^{2}=0.36, p<0.05\right.$, Fig. 5B). Hence, 346the lower the plant height, the higher its biomass at high compared to low $\mathrm{N}$ supply. Overall, 347these two results indicate that simulated species response to cutting frequency and $\mathrm{N}$ 348fertilization varies with plant functional traits and therefore with the functional strategy of 349species.

350

\subsection{Plant plasticity and simulated above-ground productivity in monocultures}

352The role of plasticity for ANPP and its stability along cutting frequency, $\mathrm{N}$ supply and light 353gradients was tested with three grass species that are representative of contrasting $\mathrm{N}$ strategies 354(Maire et al., 2009) (Fig. 6, Table 2A). The full model (FP) provided a higher ANPP (Tukey’s 355post-ANOVA comparison of multiple means, $p<0.05$ ) than other model versions that 356restricted plasticity and coordination (Fig. 6). An intermediate ANPP was obtained for model 357versions without tiller dynamics and/or root, shoot morphogenesis $\left(\mathrm{RP}_{1}, \mathrm{RP}_{2}, \mathrm{RP}_{3}\right.$ and $\mathrm{RP}_{4}$ 358versions). Model versions which, moreover, suppressed coordination between shoot structures 359and roots, or between shoot structures and leaf proteins $\left(\mathrm{RP}_{5}\right.$ and $\left.\mathrm{RP}_{6}\right)$ had significantly lower 360ANPP (Tukey, $p<0.05$ ) than other versions. The large role of plasticity for ANPP was 361underlined by a $51 \%$ share of total variance for this factor and its interactions with others.

362 Radiation and nitrogen captures (FAPAR and $S_{u}$, respectively) also varied strongly with 363plasticity level (42 and $32 \%$ of total variance, Table 2A). An explicit root morphogenesis 364 $\left(\mathrm{RP}_{1}, \mathrm{RP}_{2}\right.$ and $\left.\mathrm{RP}_{4}\right)$ significantly increased root uptake activity $\left(S_{u}\right)$ compared to model 
365versions without root morphogenesis and architecture (Tukey, $p<0.05$, data not shown). An 366explicit shoot morphogenesis (FP, $\mathrm{RP}_{1}$ and $\mathrm{RP}_{2}$ versions) increased the absorbed radiation 367(FAPAR) compared to intermediate plasticity $\left(\mathrm{RP}_{3}\right.$ and $\left.\mathrm{RP}_{4}\right)$ (data not shown).

368 With full plasticity (FP), the three grass species showed contrasting behaviors in response 369to environmental gradients. ANPP responses to $\mathrm{N}$ fertilization indicated a strong increase for 370all species, except F. arundinacea which reached a plateau (Fig. 6). ANPP responses to 371cutting frequency were smaller than with $\mathrm{N}$ supply and displayed contrasted slopes among 372species (see FP Fig. 6). F. arundinacea reached its optimum ANPP around 3 cuts per year; A. 373elatius around 6 cuts $\mathrm{yr}^{-1}$ and A. odoratum between 6 and 8 cuts $\mathrm{yr}^{-1}$ (Fig. 6). F. arundinacea 374ANPP decreased strongly with increasing shade, while the two other species were less 375affected (Fig. 6). In contrast to the full model version (FP), there was almost no increase in 376ANPP for the least plastic versions $\left(\mathrm{RP}_{5}\right.$ and $\left.\mathrm{RP}_{6}\right)$ when light and $\mathrm{N}$ supply levels were 377increased and when disturbance level was reduced (Fig. 6).

378

\subsection{Plasticity, productivity and dominance in binary mixtures}

380Within binary mixtures, the fraction of total variance (12, 24 and 33\% for ANPP, FAPAR and $381 S_{\mathrm{u}}$, respectively, Table 2B) attributed to the plasticity level was relatively smaller than in 382monocultures. However, the plasticity x species interaction explained also a substantial share 383of the total variance (17 and 39\%, respectively) of ANPP and of FAPAR. The decline in 384ANPP at reduced plasticity levels was not systematically observed in mixtures. However, $385 A N P P$ was always low when growth partitioning coordination was suppressed $\left(\mathrm{RP}_{5}, \mathrm{RP}_{6}\right.$, Fig. 3867).

387 In simulated binary mixtures, the dominance of $F$. arundinacea markedly declined with 388cutting frequency (Fig. 7). At three cuts per year, this tall grass overcompeted simulated $A$. 389odoratum and A. elatius, which were conversely dominant at higher cutting frequencies (Fig. 
3907). This disturbance induced change in dominance became less marked when root and shoot 391morphogenesis were not modeled explicitly $\left(\mathrm{RP}_{1}\right.$ and $\left.\mathrm{RP}_{2}\right)$ and was suppressed when growth 392partitioning coordination was knocked out $\left(\mathrm{RP}_{5}\right.$ and $\left.\mathrm{RP}_{6}\right)$. In the latter case, the ANPP of 393simulated F. arundinacea was always close to zero (Fig. 7).

394 Within simulated mixtures of $A$. odoratum and A. elatius, A. elatius became increasingly 395dominant at high compared to low frequency when full plasticity was included. In contrast, 396when explicit root and shoot morphologies were suppressed $\left(\mathrm{RP}_{2}, \mathrm{RP}_{3}\right.$ and $\left.\mathrm{RP}_{4}\right)$, A. odoratum 397was favored by an increased cutting frequency (Fig. 7). Therefore, the outcome of simulated 398biotic interactions depended upon model assumptions on the degree of plant plasticity.

4004. Discussion

401By combining an individual-centred approach with coordination hypotheses, we have 402developed a mechanistic model linking plant functional traits, plant population and plant 403community dynamics and ecosystem processes (e.g. net primary productivity). In agreement 404with our initial hypothesis, we have shown through a modeling experiment that both 405individual plant plasticity and population plasticity are needed to maintain grass species 406fitness (i.e. above-ground net primary productivity) along gradients of resource levels 407(nitrogen, light), disturbance (cutting frequency) and competition (mixtures vs. 408monocultures). Moreover, emergent properties arising from the model with full plasticity 409account for four well-established empirical laws: i) resilience to defoliation and to $\mathrm{N}$ 410deprivation, ii) critical $\mathrm{N}$ decline during stand growth, iii) self-thinning and iv) trait mediated 411species productivity response to defoliation and $\mathrm{N}$ deprivation. Furthermore, simplified 412versions of the model lacking processes controlling plant plasticity and population plasticity 413display a lower net primary productivity as compared to the full plastic model. 


\subsection{Emergent properties of the model}

416At full complexity, the model presents emergent properties, which account for four well417established empirical laws.

418 First, the Gemini model re-establishes a functional balance after a disturbance caused by 419defoliation and after a stress caused by $\mathrm{N}$ deprivation. After a defoliation event, a preferential 420partitioning of substrates first to leaf proteins and then to shoot structures is induced at the 421expense of roots. This response to defoliation replenishes leaf $\mathrm{N}$ content and increases leaf 422area. Conversely, after $\mathrm{N}$ deprivation, preferential partitioning to roots takes place and the 423activity of root transporters is de-repressed which also contributes to increased $\mathrm{N}$ uptake, 424thereby restoring a functional equilibrium and a coordination of leaf photosynthesis. Hence, 425through changes in the relative sizes and physiological activities of roots and shoots, plant 426growth will again be co-limited by multiple resources capture (photosynthetically active 427radiation, atmospheric $\mathrm{CO}_{2}$ and inorganic $\left.\mathrm{N}\right)$.

428 Second, the model accounts for the decline in critical $\mathrm{N}$ concentration during stand 429regrowth. Even when there is ample supply of $\mathrm{N}$, plant shoot $\mathrm{N}$ concentration declines during 430growth within dense canopies. This observation led to the development of a law relating 431critical shoot $\mathrm{N}$ concentration (see Methods) and stand dry matter accumulation by a negative 432power function (Lemaire et al., 2008). For LAI values below ca. 5, this empirical law is well 433accounted for by the model. This shows that when leaves become gradually shaded, changes 434in leaf proteins to structure ratio support the hypothesis of leaf photosynthesis coordination 435(Maire, 2009). Through changes in the $Q$ partitioning variable, an increasing fraction of 436shaded leaves induces the simulated decline in shoot $\mathrm{N}$ concentration during canopy growth. 437In contrast, simulated $\mathrm{N}$ content of leaves in full light at the top of the canopy remain constant 438(data not shown), in agreement with previous measurements (Gastal and Lemaire, 2002). At 439high $L A I$ values (above 5), the empirical critical $\mathrm{N}$ content is slightly above the coordinated 
440simulated leaf $\mathrm{N}$ content. Overall, it is remarkable that the value and plasticity of C-N 441stoichiometry (see Gruber and Galloway, 2008) during autotrophy is an emergent property of 442coordinated resource acquisition by plants.

443 Third, self-thinning, a well-established empirical law is also predicted. The self-thinning 444rule relates plant mass to plant density in crowded, even-aged stands by a power-law equation 445with a negative exponent which is usually close in absolute value to $3 / 2$. The rule is widely 446accepted as an empirical generalization and quantitative law that applies across the plant 447kingdom (e.g. Sackville-Hamilton et al., 1995; West et al., 1999). It is remarkable that the 448combination in the GEMINI model of detailed ecophysiological and morphogenetic processes at 449the individual plant scale results in a self-thinning rule relating size and density of tillers 450across grass species. Interestingly, both the model and the measurements show a negative 451exponent close to one, and therefore substantially lower than the $3 / 2$ exponent (but see 452Enquist and Niklas, 2002). This could be caused by the physiological integration among tillers 453within clonal grasses which tends to reduce tiller mortality within crowded stands (De Kroon 454et al., 1992).

455 Finally, another emerging model property concerns its ability to explain some of the 456observed trait mediated species productivity responses to defoliation and $\mathrm{N}$ deprivation. The 457correlation between the log-response ratio of ANPP to cutting frequency and SLA is in good 458agreement with previous observations (Caldwell, 1981; Westoby, 1999) showing that high 459SLA favors fast leaf regrowth and hence a tolerance response to defoliation, by increasing the 460rate of leaf recovery (Gross et al., 2007). Similarly, the negative correlation between the log461response ratio of $A N P P$ to $\mathrm{N}$ supply and plant height is consistent with the positive 462relationship which was found between plant height and $\mathrm{N}$ conservation with the same grass 463species (Maire et al., 2009).

464 


\subsection{Role of plasticity}

466The plasticity of traits can be influenced by allometric or physiological constraints and some 467species might be less plastic than others depending on their traits (Givnish, 2002; Enquist and 468Niklas, 2002; Weiner, 2004). However, to date, few studies have investigated relationships 469between trait plasticity and the variations of physiology, morphology and growth across plant 470species (Ackerly and Sultan, 2006).

471 The present modeling study supports the hypothesis that plasticity favors the resilience 472along nutrients and disturbance gradients of plant production and competitive ability (Figures 4736, 7, 8) in agreement with previous reports (e.g. Soussana and Lafarge, 1998). With an 474individual centered-model such as GeminI, suppressing axis demography ( $\mathrm{RP}_{1}$ version) halved 475the overall mean ANPP simulated by the model. Plastic adjustments in tiller density have been 476observed in response both to cutting frequency and to nitrogen supply (Lemaire and 477Chapman, 1996). Indeed, the negative exponent between tiller size and density shows that 478these two traits co-vary both within and across grass species. Imposing a constant tiller 479density, leads either to excess $\mathrm{C}$ and $\mathrm{N}$ substrates (under environmental conditions favorable 480for growth), or to substrate deficiency whenever resources become too limited to support the 481tiller population (data not shown).

482 Although suppressing shoot morphogenesis simulation $\left(\mathrm{RP}_{2}\right)$ did not affect significantly 483ANPP, suppressing both root morphogenesis and axis demography $\left(\mathrm{RP}_{3}\right)$ reduced by a factor 484of four ANPP in comparison to the full model. Therefore, root architecture and turnover 485appear to have a major role in an individual-centred model, since they contribute to the 486stability of yield along resource and disturbance gradients. Finally, further suppressing growth 487coordination $\left(\mathrm{RP}_{5}\right.$ and $\left.\mathrm{RP}_{6}\right)$ leads to a mean $A N P P$ that is divided by a factor of 1.25 or more 488compared to the full model, which underlines the major role of growth and photosynthesis 489coordination (Fig. 8). 
490 These simulations reveal that although simple compartment-based models may be 491successful at predicting the instantaneous fluxes exchanged between vegetation and the 492environment, they are not applicable at the individual plant and population scales. Given the 493large variability in resource levels and in microclimate experienced by individual plants 494within stands, most assumptions of simple models (e.g. constant radiation and nitrogen use 495efficiencies) do not hold at this scale (Faurie et al., 1996; Gastal and Lemaire, 2002). In 496contrast, individual centered models show that plasticity in the form and function of 497individual plants stabilizes productivity, light interception and $\mathrm{N}$ uptake, as well as radiation 498and $\mathrm{N}$ use efficiencies (data not shown).

499 When applying the full model to binary mixtures, simulated grass species dominance was 500consistent with observations of:

$501-$ an increased dominance of grass species which have high plant stature and

502 conservative traits (such as F. arundinacea) at low compared to high cutting frequencies, 503 compared both to short and to tall exploitative grasses (e.g. A. odoratum and A. elatius), 504 (Louault et al., 2005; Pontes et al., 2011);

505- $\quad$ an increased dominance of tall vs. short exploitative grass species (A. elatius 506 vs. A. odoratum) at low compared to high cutting frequencies (Grime, 1979; Pontes et al., 507 2011).

508Without an explicit root and shoot morphogenesis, grass species dominance was not altered 509along a disturbance gradient. Under increased disturbance by cutting, species ability to rapidly 510emit new leaves is an important trait that favors competitive ability for light capture 511(Cingolani et al., 2005). Therefore, without explicit shoot morphogenesis, this capacity is lost 512and changes in dominance with cutting frequency are not simulated adequately anymore. 


\subsection{Model complexity}

517There is a common understanding that the complexity of a particular system is linked to the 518difficulty in predicting the system properties despite a detailed knowledge of the system 519elements and their relationships (Weaver, 1948; Heylighen, 2008). Complexity can be seen 520either as disorganized or as organized. The latter case applies to our study since we consider 521non-random and correlated interactions between a range of processes at the root, shoot, plant, 522population, community and ecosystem scales. We have retained the emergence concept since 523our simulated system shows plasticity properties which are not dictated by the elementary 524parameters which are used for modeling these processes. To understand such organized 525complexity with emergent properties computer simulation was necessary (Hill, 1996).

526 In this way, we changed the granularity of different submodels of GEMINi in order to 527test their pertinence for the plant fitness in a given environment. This has been partially 528integrated in the software architecture by activating / deactivating some submodels (e.g. leaf 529and root architectures) that are replaced by more simplistic behaviors. However this 530replacement is not fully automated in Gemins, and it should be interesting for a mechanistic 531model like Gemini to push away the degree of granularity at will. The difficulty of changing 532model granularity lies in the issue of coupling models. Coupling models requires a framework 533and a methodology of development (Davis, 2001) accounting for the exchange of data 534between models which should be considered itself as a model (Winiwarter, 2005) as well as 535for the ordering of variables during the integration process, because a dependency between 536variables implies an order of computation. This issue requires being able to analyze the 537formulas when coupling models to find the dependencies between variables and set up a new 538ordering in the integration process. As Gemins is developed in $\mathrm{C}^{++}$language, one can consider 
539designing an EDSL (Embedded Design Specific Language) based on metaprogramming and 540operators overloading (Fowler, 2010).

\section{Conclusion}

542The GEMINI model provides a consistent trait-based mechanistic framework for modeling the 543role of grass diversity and plasticity on community dynamics and ecosystem functioning. In 544this paper, we have shown from in-silico experiments the role of morphological (root and 545shoot morphology) and physiological (leaf $\mathrm{N}$ content, leaf photosynthesis) plasticity, as well 546as population (axis density) plasticity, for plant population fitness (i.e. net primary 547productivity) across resource, disturbance and competition gradients. Moreover, we have 548shown that model versions for which plasticity has been suppressed are not able to reproduce 549observed changes in net primary productivity across environment and competition gradients. 550Therefore, the details of physiological and morphological mechanisms allowing adaptive 551plasticity in the Gemini model are both necessary and sufficient (in agreement with the 552parsimony principle) to simulate major trends in perennial grasses productivity and 553dominance. This modeling experiment shows that along environmental and competition 554gradients the plasticity of plant form and function contributes to maintain the coordination of 555multiple resource capture and, hence, to sustain productivity and dominance.

556

\section{Acknowledgements}

558This study was financially supported by the French ANR DISCOVER (ANR-05-BDIV-010-01) 559and ANR QDIV (ANR-05-BDIV-009-01) projects and by the FEDER, 'l'Europe s'engage en 560région Auvergne'. V. Maire was funded by a Ph-D grant of French research ministry. We 561thank Hoglah Dasari and two anonymous referees which provide helpful comments and 562improvements on previous versions of the manuscript. 


\section{References}

564Ackerly, D., Sultan, S., 2006. Mind the gap: the emerging synthesis of plant 'eco-devo'. New 565 Phytol. 170, 648-653.

566Caldwell, M.M., 1981. Plant response to solar ultraviolet radiation. Pages 170-194 in L. e. A. 567 éd., editor. Physiological plant ecology I. Springer Verlag, Berlin.

568Chapin III, F.S., 1991. Integrated responses of plants to stress. A centralized system of 569 physiological responses. Bioscience 41, 29-36.

570Chen, J.L., Reynolds, J.F., Harley, P.C., Tenhunen, J.D., 1993. Coordination theory of leaf 571 nitrogen distribution in a canopy. Oecologia 93, 63-69.

572Cingolani, A.M., Posse, G., Collantes, M.B., 2005. Plant functional traits, herbivore 573 selectivity and response to sheep grazing in Patagonian steppe grasslands. J. App. Ecol. $574 \quad 42,50-59$.

575Davidson, R.L., 1969. Effect of root/leaf temperature differentials on root/shoot ratios in some 576 pasture grasses and clover. Ann. Bot. 33, 561-569.

577Davis, P.K., 2001. Adaptive designs for multiresolution multiperspective modeling 578 (MRMPM). Pages 27-52 in Discrete event modeling and simulation technologies, 579 Springer-Verlag.

580De Jong, G., 2005. Evolution of phenotypic plasticity: patterns of plasticity and the 581 emergence of ecotypes. New Phytol. 166, 101-117.

582De Kroon, H., Hara, T., Kwant, R., 1992. Size hierarchies of shoots and clones in clonal herb 583 monocultures: do clonal and non-clonal plants compete differently? Oikos 63, 410-419.

584Enquist, B.J., Niklas, K.J., 2002. Global allocation rules for patterns of biomass partitioning 585 in seed plants. Science 295, 1517-1520.

586Faurie, O., Soussana, J.-F., Sinoquet, H., 1996. Radiation interception, partitioning and use in 587 grass-clover mixtures. Ann. Bot. 77, 35-45. 
588Fowler, M., 2010. Domain-specific languages. Addison—Wesley.

589Gastal, F., Lemaire, G., 2002. N uptake and distribution in crops: an agronomical and 590 ecophysiological perspective. J. Exp. Bot. 53, 789-799.

591Givnish, T.J., 2002. Ecological constraints on the evolution of plasticity in plants. Evol. Ecol. 592 16(3), 213-242.

593Grassein, F., Till-Bottraud, I., Lavorel, S., 2010. Plant resource-use strategies: the importance 594 of phenotypic plasticity in response to a productivity gradient for two sub-alpine species. 595 Ann. Bot. 106, 637-645.

596Grime, J.P., 1973. Competitive exclusion in herbaceous vegetation. Nature 242, 344-347. 597Grime, J.P., 1979. Plant strategies and vegetation processes. Wiley, J. \& Sons Press, 598 Chichester, UK, 222 pp.

599Grime, J.P., Mackey, J.M.L., 2002. The role of plasticity in resource capture by plants. Evol. $600 \quad$ Ecol. 16, 299-307.

601Gross, N., Suding, K.N., Lavorel, S. 2007. Leaf dry matter content and lateral spread predict 602 response to land use change for six subalpine grassland species. J. Veget. Sci. 18, 289603300.

604Gross, N., Kunstler, G., Liancourt, P., Bello, F., Suding, K.N., Lavorel, S., 2009. Linking 605 individual response to biotic interactions with community structure: a trait-based 606 framework. Funct. Ecol. 23, 1167-1178.

607Gruber, N., Galloway, J.N., 2008. An Earth-system perspective of the global nitrogen cycle. 608 Nature 451, 293-296.

609Harper, J.L., 1978. Plant relations in pastures. In: Plant relations in pastures. Csiro (eds), 610 Melbourne, Australia, p. 1-14.

611Heylighen, F., 2008. Complexity and self-organization, in: Bates, M.J., Maack, M.N. (eds.), 612 Encyclopedia of Library and Information Sciences. CRC Press, Los Angeles, USA. 
613Hilbert, D. W., Reynolds, J. F., 1991. A model allocating growth among leaf proteins, shoot 614 structure, and root biomass to produce balanced activity. Ann. Bot. 68, 417-425.

615Hill, D.R.C., 1996. Object-oriented analysis and simulation modeling. Addison Wesley 616 Longman, Boston, USA 291 pp.

617Hoglind, M., Schapendonk, A.. Van Oijen, M. 2001. Timothy growth in Scandinavia: 618 combining quantitative information and simulation modelling. New Phytol. 151, 355-367. 619Lafarge, M., Mazel, C., Hill, D.R.C., 2005. A modelling of the tillering capable of 620 reproducing the fine-scale horizontal heterogeneity of a pure grass sward and its 621 dynamics. Ecol. Model. 183, 125-141.

622Lemaire, G., Chapman, D., 1996. Tissue flows in grazed plant communities. In: Hodgson, J., 623 Illius, A.W., (eds), The Ecology and Management of Grazing Systems, Wallingford, UK, 624 p. 3-36.

625Lemaire, G., 1999. Les flux de tissus foliaires au sein des peuplements prairiaux. Eléments 626 pour une conduite raisonnée du pâturage. Fourrages 159, 203-222.

627Lemaire G., Jeuffroy, M.H., Gastal, F., 2008. Diagnosis tool for plant and crop N status in 628 vegetative stage theory and practices for crop N management. Eur. J. Agron. 28, 614-624. 629Louault, F., Pillar, V.D., Aufrere, J., Garnier, E., Soussana, J.-F., 2005. Plant traits and 630 functional types in response to reduced disturbance in a semi-natural grassland. J. Veget. 631 Sci. 16, 151-160.

632Maire, V., Martre, P., Kattge, J., Gastal, F. Esser, G. Fontaine, S., Soussana, J.-F. The coordination of 633 leaf photosynthesis links $\mathrm{C}$ and $\mathrm{N}$ fluxes in $\mathrm{C}_{3}$ plant species. Accepted in PlosOne.

634Maire, V., Gross, N., Pontes, L., Picon-Cochard, C., Soussana, J.-F., 2009. Trade-off between 635 root nitrogen acquisition and shoot nitrogen utilization across 13 co-occurring pasture 636 grass species. Funct. Ecol. 23, 668 - 679. 
637Maire, V., 2009. From functional traits of grasses to the functioning of grassland ecosystem: a 638 mechanistic modelling approach. PhD thesis, Blaise Pascal University, Clermont-Ferrand, 639 France, 300 pp.

640Neuteboom, J.H., Lantinga, E.A., 1989. Tillering potential and relationship between leaf and 641 tiller production in perennial Ryegrass. Ann. Bot. 63, 265-270.

642Pontes, L.D.S., Soussana, J.-F., Louault, F., Andueza, D., Carrere, P., 2007. Leaf traits affect 643 the above-ground productivity and quality of pasture grasses. Funct. Ecol. 21, 844-853. 644Pontes, L.D., Louault, F., Carrere, P., Maire, V., Andueza, D., Soussana, J.F. 2010. The role 645 of plant traits and their plasticity in the response of pasture grasses to nutrients and cutting 646 frequency. Ann. Bot. 105, 957-965.

647Pontes, L.D., Maire, V., Louault, F., Soussana, J.F., Carrere, P., 2011. Impacts of species 648 interactions on grass community productivity under contrasting management regimes. 649 Oecologia in press.

650Sackville-Hamilton, N.R., Matthew, C., Lemaire, G., 1995. In defence of the $-3 / 2$ boundary 651 rule: a re-evaluation of self-thinning concepts and status. Ann. Bot. 76, 569-577.

652Soussana, J.-F., Lafarge, M., 1998. Competition for resources between neighbouring species 653 and patch scale vegetation dynamics in temperate grasslands. Ann. Zootechn. 47, 371654382.

655Soussana, J.F., Maire, V., Gross, N., Hill, D., Bachelet, B., Pages, L., Martin, R., Wirth, C., 656 2012. Gemins: a grassland model simulating the role of plant traits for community 657 dynamics and ecosystem functioning. Part I: Parameterization and Evaluation. Ecol. 658 Model.

659Suding, K.N., Goldberg, D.E., Hartman, K.M., 2003. Relationships among species traits: 660 Separating levels of response and identifying linkages to abundance. Ecology 84, 1-16. 
661Sultan, S.E., 2004. Promising directions in plant phenotypic plasticity. Perspect. Plant Ecol. 6, $662 \quad 227-233$.

663Tilman, D., 1984. Plant dominance along an experimental nutrient gradient. Ecology 65, $664 \quad 1445-1453$.

665Tilman, D., 1990. Constraints and tradeoffs: toward a predictive theory of competition and 666 succession. Oikos 58(1): 3-15.

667Useche, A., Shipley, B., 2010a. Interspecific correlates of plasticity in relative growth rate 668 following a decrease in nitrogen availability. Ann. Bot. 105, 333-339.

669Useche, A., Shipley, B., 2010b. Plasticity in relative growth rate after a reduction in nitrogen 670 availability is related to root morphological and physiological responses. Ann. Bot. 106, $671 \quad 617-625$.

672Van Ruijven, J., Berendse, F., 2003. Positive effects of plant species diversity on productivity 673 in the absence of legumes. Ecol. Lett. 6, 170-175.

674Weaver, W., 1948. Science and complexity. American Scientist 36, 536-544.

675Weiner, J., 2004. Allocation, plasticity and allometry in plants. Perspectives Plant Ecol. Evol. 676 System. 6, 207-215.

677West, G.B., Brown, J.H., Enquist, B.J., 1999. A general model for the structure and allometry 678 of plant vascular systems. Nature 400, 664-667.

679Westoby, M., 1999. The LHS strategy scheme in relation to grazing and fire. In: People and 680 rangelands: building the future. International Rangeland Congress, Inc, Aitkenvale 681 Australia, Proceedings of the VI International Rangeland Congress, Townsville, 682 Queensland, Australia, Volumes 1 and 2, p. 893-896

683Wilson, J.B., 1988. A review of evidence on the control of shoot : root ratio, in relation to 684 models. Ann. Bot. 61, 433-449. 
685Winiwarter, W., 2005. The interface problem in model coupling: examples from atmospheric 686 science. In Proceedings of the OICMS 2005 Conference, p. 43-48.

687Wu, Z., Skjelvag, A.O., Baadshaug, O.H., 2004. Quantification of photoperiodic effects on 688 growth of Phleum pratense. Ann. Bot. 94, 535-543.

689Yin, X., Schapendonk, A., 2004. Simulating the partitioning of biomass and nitrogen between 690 roots and shoot in crop and grass plants. Njas-Wageningen J. Life Sci. 51, 407-426. 


\section{Table Captions}

692Table 1. Parameter calibration of Gemins for reduced plasticity versions $\left(\mathrm{RP}_{1-6}\right)$. The 693parameterization of the full plasticity version (FP) is reported by Soussana et al. (2012). A) 694Modeling experiment evaluating the role of plant plasticity. The full Gemini model (FP) was 695compared with reduced demographic and morphogenetic plasticity (from $\mathrm{RP}_{1}$ to $\mathrm{RP}_{4}$ ) and 696with reduced coordination of growth $\left(\mathrm{RP}_{5}\right.$ and $\left.\mathrm{RP}_{6}\right)$ versions. $\mathrm{D}_{\mathrm{sp}}$, indicates that a dynamic 697variable is calculated by the model. $\mathrm{P}_{\mathrm{sp}}$, indicates that a parameter has been calibrated for each 698species using pseudo-equilibrium FP output variables for the C- $\mathrm{N}+$ experimental treatment 699(see Methods). B) Species-specific parameter values $\left(\mathrm{P}_{\mathrm{Sp}}\right)$ in reduced plasticity versions. 700Abbreviations: intcl, clonal integration; Tsen $_{0}$, axis lifespan; $q_{1}$ and $q_{2}$, power coefficients 701varying the degree of control on partitioning between shoot and root structures and between 702shoot structures and leaf proteins, respectively; $C_{\mathrm{H}}$, leaf canopy density; $L A R$, leaf area ratio;

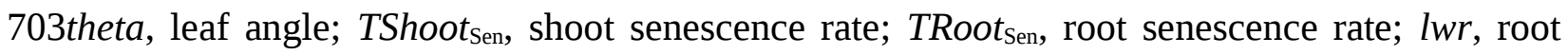
704area ratio. nd; not determined.

705

706Table 2. ANOVA (General Linear model) for the effects of plant species (A. odoratum, A. 707elatius and $F$. arundinacea), plant plasticity ( $\mathrm{FP}, \mathrm{RP}_{1}$ to $\mathrm{RP}_{6}$ versions of the model, see 708Methods), cutting frequency, incident light and nitrogen supply factors on simulated above709ground net primary productivity (ANPP), fraction of absorbed photosynthetically active 710radiation (FAPAR) and nitrogen uptake rate $(\mathrm{Su})$. A) Monocultures, B) Binary mixtures. 711Abbreviations: df, degree of freedom; Expl. Var., percentage of variance explained; ns, not 712significant. 


\section{Figure Captions}

715

716Figure 1. Conceptual design of a modeling experiment for evaluating the role of plant 717plasticity. Aboveground net primary productivity (ANPP) is compared between full model 718(FP), reduced demographic and morphogenetic plasticity model versions $\left(\mathrm{RP}_{1}\right.$ to $\left.\mathrm{RP}_{4}\right)$ and 719reduced coordination of growth $\left(\mathrm{RP}_{5}\right.$ and $\left.\mathrm{RP}_{6}\right)$ model versions.

720

721Figure 2. Effects of a cut (at $5 \mathrm{~cm}$ height on day 0) and of $\mathrm{N}$ deprivation (from 0.25 to 0.05 722gN m $\mathrm{g} \mathrm{d}^{-1}$ on day 110) on the $P$ and $Q$ variables partitioning assimilates between shoot and 723root structures, and between shoot structures and leaf photosynthetic proteins, respectively. 724Simulations were run with $D$. glomerata under a constant environment. Note that small 725oscillations in $P$ and $Q$ dynamics after disturbance by cutting and $\mathrm{N}$ deprivation are caused by 726changes in leaf and in root numbers (emission and mortality).

727

728Figure 3. Simulated and empirical relationships between shoot $N$ concentration and shoot dry 729matter during regrowth after a cut (open circles) for the C-N+ treatment. Open circles show 730simulation results. The solid line shows the empirical law relating critical shoot $\mathrm{N}$ 731concentration (Y, \%) and shoot dry-matter $\left(\mathrm{X}, \mathrm{t} \mathrm{DM} \mathrm{ha}^{-1}\right)$ as $\mathrm{Y}=4.8 \mathrm{X}^{-0.32}$ (Lemaire et al., 7322008). The dashed line shows the fit of a power law to simulated results for shoot dry-matter 733values above 2.5 t DM ha-1.

734

735Figure 4. Relationships between simulated mean tiller mass $\left(W_{\mathrm{G}}\right)$, simulated shoot mass ( $W_{\mathrm{S}}$ $\left.736+W_{\mathrm{P}}\right)$ and simulated mean tiller density (A); and between observed shoot mass and observed 737mean tiller density (B) across 13 grass species. Species abbreviations are: Alopecurus 738pratensis (Ap), Anthoxanthum odoratum (Ao), Arrhenatherum elatius (Ae), Dactylis 
739glomerata (Dg), Elytrigia repens (Er), Festuca arundinacea (Fa), Festuca rubra (Fr), Holcus 740lanatus (Hl), Lolium perenne (Lp), Lolium perenne cultivar $(\mathrm{Cl})$, Phleum pratense (Php), Poa 741pratensis (Pp), Poa trivialis (Pt), Trisetum flavescens (Tf). In A, simulated relationships for 742mean tiller mass $\left(W_{\mathrm{G}}\right)$ and for shoot mass $\left(W_{\mathrm{S}}+W_{\mathrm{P}}\right)$ are displayed in capitals and in small 743letters, respectively. Simulations were run for 10 years in monocultures at 3 cuts per year and 744for $360 \mathrm{kgN} \mathrm{ha}^{-1} \mathrm{yr}^{-1} \mathrm{~N}$ fertilizer supply. Slope and intercepts of SMA regressions were 745calculated according to Warton et al. (2006). In B, the observations of tiller density and shoot 746mass of grass species were measured under equivalent management in the site of Theix and 747were fully commented in Pontes et al. (2007) and in Soussana et al. (2012).

748

749Figure 5. Relationships between plant functional traits and above-ground net primary 750productivity (ANPP) response (log response ratio, LNRR, Suding et al. 2003) to management 751changes of 12 grass species simulated by GEMINI in monoculture. (A) Relationship between 752specific leaf area (SLA) and response to cutting intensity increase (LNRR(cut), from 3 to 6 cut 753yr ${ }^{-1}$ ); (B) Relationship between plant height and response to $\mathrm{N}$ fertilization increase 754(LNRR(N), from 120 to $360 \mathrm{kgN} \mathrm{ha}^{-1} \mathrm{yr}^{-1}$ ).

\section{5}

756Figure 6. Simulated above-ground net primary productivity (ANPP) of three grass 757monocultures (A. odoratum, A. elatius, F. arundinacea) along disturbance (cutting frequency: 7581, 3, 6 and 8 cuts $\mathrm{yr}^{-1}$ ), nitrogen supply (60, 120 and $360 \mathrm{kgN} \mathrm{ha}^{-1} \mathrm{yr}^{-1}$ from substrate and 759fertilizer) and light (100, 80 and 60\% of incident daily PPFD) gradients. The full GEMINI 760model (FP) was compared with versions increasingly (from $\mathrm{RP}_{1}$ to $\mathrm{RP}_{6}$ ) restricting plasticity 761and coordination of plant form and function (see Methods). $\mathrm{RP}_{1}$, no axis turnover; $\mathrm{RP}_{2}$, same 762as $\mathrm{RP}_{1}$ but without explicit root morphogenesis; $\mathrm{RP}_{3}$, same as $\mathrm{RP}_{1}$ but without explicit shoot 763morphogenesis; $\mathrm{RP}_{4}$, same as $\mathrm{RP}_{1}$ but without explicit root and shoot morphogenesis; $\mathrm{RP}_{5}$, 764same as $\mathrm{RP}_{4}$ with equal distribution of assimilates to leaf structure and leaf proteins; $\mathrm{RP}_{6}$, 
765same as $\mathrm{RP}_{4}$ with equal distribution of assimilates to leaf structure and roots. The effects of 766plasticity level (P), of environmental gradients (C: cutting frequency, $\mathrm{N}$ : nitrogen fertilization 767level, L: light level) and of their interactions were tested by ANOVA (see SI3 for details) and 768are shown with their corresponding $p$-level.

769

770Figure 7. Simulated above-ground net primary productivity (ANPP) of binary mixtures of $A$. 771odoratum, A. elatius and F. arundinacea along a cutting frequency (3, 6 and 8 cuts per year) 772gradient. Figures in the same row compare the two component species within a binary 773mixture. The full Gemins model (FP) was compared with versions increasingly (from $\mathrm{RP}_{1}$ to 774RP ${ }_{6}$ ) restricting plasticity and coordination of plant form and function. For abbreviations, see 775Figure 8.

776

777Figure 8. Simulated plasticity levels ratios for mean above-ground net primary productivity 778(ANPP) of grass species (A. odoratum, A. elatius and F. arundinacea) in monocultures and in 779binary mixtures across all $\mathrm{N}$ fertilization, cutting regime and light gradients. The plasticity 780level ratio was calculated as the ratio of a given plasticity level (FP, $\mathrm{RP}_{1}$ to $\mathrm{RP}_{5}$ ) to the lowest 781plasticity level $\left(\mathrm{RP}_{6}\right)$. 
782 Table 1.

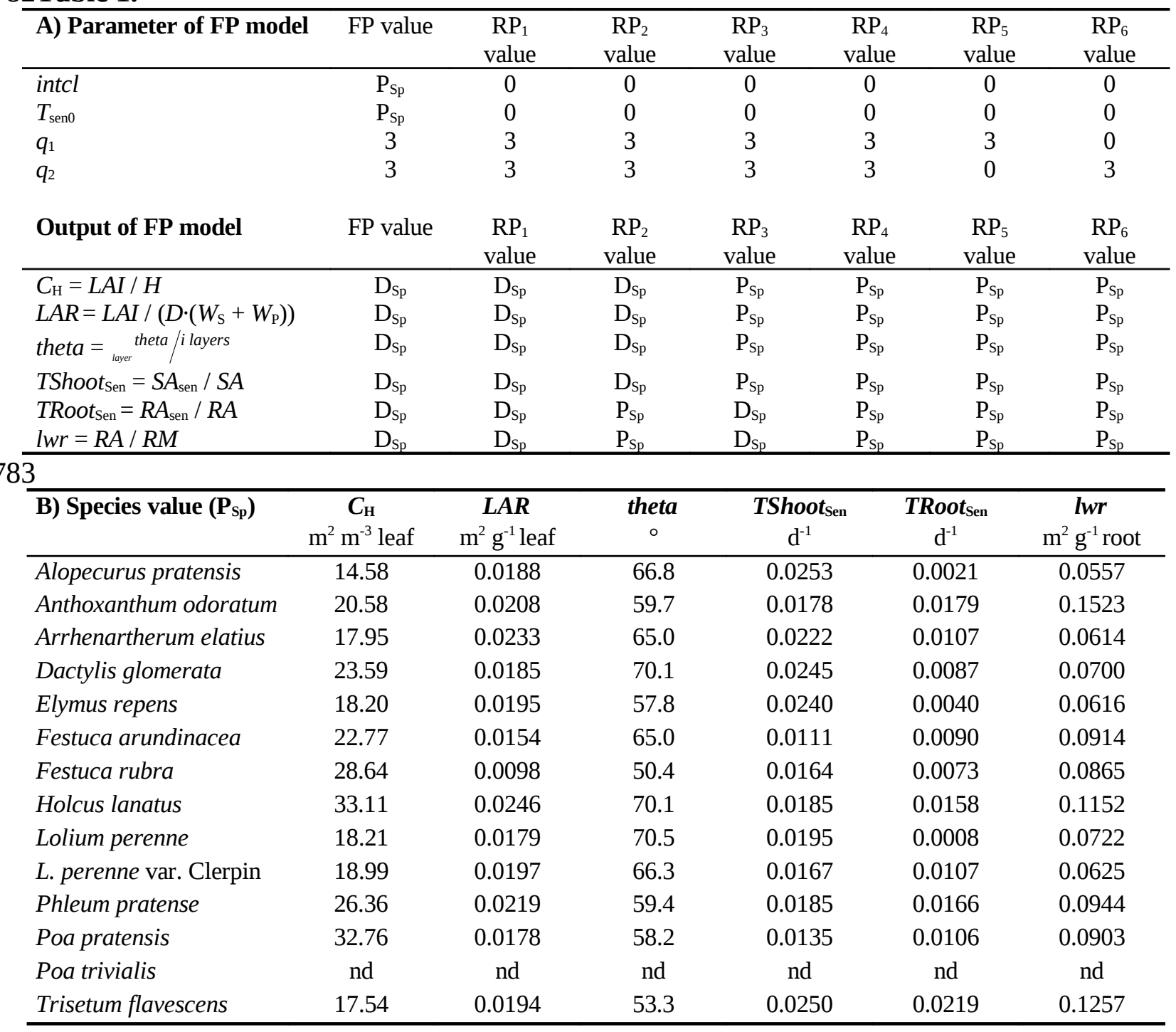

784 
785Table 2

\begin{tabular}{|c|c|c|c|c|c|c|c|}
\hline \multirow{2}{*}{$\begin{array}{l}\text { A) Monoculture } \\
\text { Factors }\end{array}$} & \multirow[b]{2}{*}{ df } & \multicolumn{2}{|c|}{$D M Y$} & \multicolumn{2}{|c|}{ FAPAR } & \multicolumn{2}{|c|}{$\mathrm{Su}$} \\
\hline & & Expl. Var. & $\boldsymbol{P}$ & Expl. Var. & $\boldsymbol{P}$ & Expl. Var. & $\boldsymbol{P}$ \\
\hline Species & 2 & 5.25 & $<0.001$ & 2.7 & $<0.001$ & 24.0 & $<0.001$ \\
\hline Plasticity & 6 & 24.03 & $<0.001$ & 42.2 & $<0.001$ & 32.3 & $<0.001$ \\
\hline $\mathrm{C}$ & 2 & 10.03 & $<0.01$ & 6.3 & $<0.001$ & 0.7 & $<0.01$ \\
\hline $\mathrm{N}$ & 2 & 21.91 & $<0.001$ & 11.8 & $<0.001$ & 27.8 & $<0.001$ \\
\hline Light & 2 & 0.47 & $<0.01$ & 3.7 & $<0.001$ & 3.0 & $<0.001$ \\
\hline Species*Plasticity & 12 & 14.24 & $<0.001$ & 16.6 & $<0.001$ & 5.0 & $<0.001$ \\
\hline Species*C & 6 & 0.74 & $<0.01$ & - & ns & - & ns \\
\hline Species*N & 4 & 0.59 & $<0.01$ & - & ns & - & ns \\
\hline Species*Light & 4 & 0.79 & $<0.01$ & 2.7 & $<0.001$ & - & ns \\
\hline Plasticity*C & 18 & 11.48 & $<0.001$ & - & ns & 0.6 & $<0.01$ \\
\hline Plasticity*N & 12 & 6.58 & $<0.001$ & 3.3 & $<0.001$ & 2.2 & $<0.001$ \\
\hline Plasticity*Light & 12 & 2.57 & $<0.001$ & 7.5 & $<0.001$ & 4.3 & $<0.001$ \\
\hline $\mathrm{C} * \mathrm{~N}$ & 6 & 1.32 & $<0.001$ & 1.0 & $<0.01$ & - & ns \\
\hline C*Light & 6 & - & ns & - & ns & - & ns \\
\hline $\mathrm{N}^{*}$ Light & 4 & - & ns & 2.1 & $<0.001$ & - & ns \\
\hline Total & 652 & $r^{2}=75.0$ & $<0.001$ & $r^{2}=67.2$ & $<0.001$ & $r^{2}=88.1$ & $<0.001$ \\
\hline \multicolumn{2}{|l|}{ B) Mixture } & \multicolumn{2}{|c|}{ DMY } & \multicolumn{2}{|c|}{ FAPAR } & \multicolumn{2}{|c|}{ Su } \\
\hline & df & Expl. Var. & $\boldsymbol{P}$ & Expl. Var. & $\boldsymbol{P}$ & Expl. Var. & $\boldsymbol{P}$ \\
\hline Mixture & 2 & 1.7 & $<0.001$ & 0.5 & $<0.01$ & 1.3 & $<0.001$ \\
\hline Species & 2 & 0.9 & $<0.001$ & - & ns & 30.2 & $<0.001$ \\
\hline Plasticity & 6 & 28.9 & $<0.001$ & 24.4 & $<0.001$ & 33.2 & $<0.001$ \\
\hline $\mathrm{C}$ & 2 & 9.3 & $<0.001$ & 2.5 & $<0.001$ & 1.0 & $<0.001$ \\
\hline $\mathrm{N}$ & 2 & 9.8 & $<0.001$ & 2.7 & $<0.001$ & 21.3 & $<0.001$ \\
\hline Light & 2 & 0.9 & $<0.001$ & - & ns & 3.0 & $<0.001$ \\
\hline Mixture*Plasticity & 12 & 3.9 & $<0.001$ & 8.6 & $<0.001$ & 1.7 & $<0.001$ \\
\hline Mixture*C & 6 & 0.7 & $<0.001$ & 2.5 & $<0.001$ & 0.2 & $<0.01$ \\
\hline Mixture*N & 4 & 0.6 & $<0.001$ & - & ns & 0.2 & $<0.001$ \\
\hline Mixture*Light & 4 & - & ns & - & ns & - & ns \\
\hline Species*Plasticity & 12 & 20.6 & $<0.001$ & 39.2 & $<0.001$ & 2.7 & $<0.001$ \\
\hline Species*C & 6 & 4.5 & $<0.001$ & 12.3 & $<0.001$ & 1.0 & $<0.001$ \\
\hline Species*N & 4 & 1.9 & $<0.001$ & 3.3 & $<0.001$ & 0.8 & $<0.001$ \\
\hline Species*Light & 4 & - & ns & - & ns & 0.1 & $<0.05$ \\
\hline Plasticity*C & 18 & 7.6 & $<0.001$ & 1.6 & $<0.05$ & 1.8 & $<0.001$ \\
\hline Plasticity*N & 12 & 4.8 & $<0.001$ & 1.7 & $<0.001$ & 0.7 & $<0.001$ \\
\hline Plasticity*Light & 12 & 2.6 & $<0.001$ & - & ns & 0.8 & $<0.001$ \\
\hline $\mathrm{C} * \mathrm{~N}$ & 6 & 1.0 & $<0.001$ & - & ns & 0.2 & $<0.01$ \\
\hline C*Light & 6 & 0.4 & $<0.05$ & - & ns & - & ns \\
\hline $\mathrm{N}^{*}$ Light & 4 & - & ns & - & ns & - & ns \\
\hline Total & 1139 & $r^{2}=67.9$ & $<0.001$ & $r^{2}=54.6$ & $<0.001$ & $r^{2}=89.1$ & $<0.001$ \\
\hline
\end{tabular}




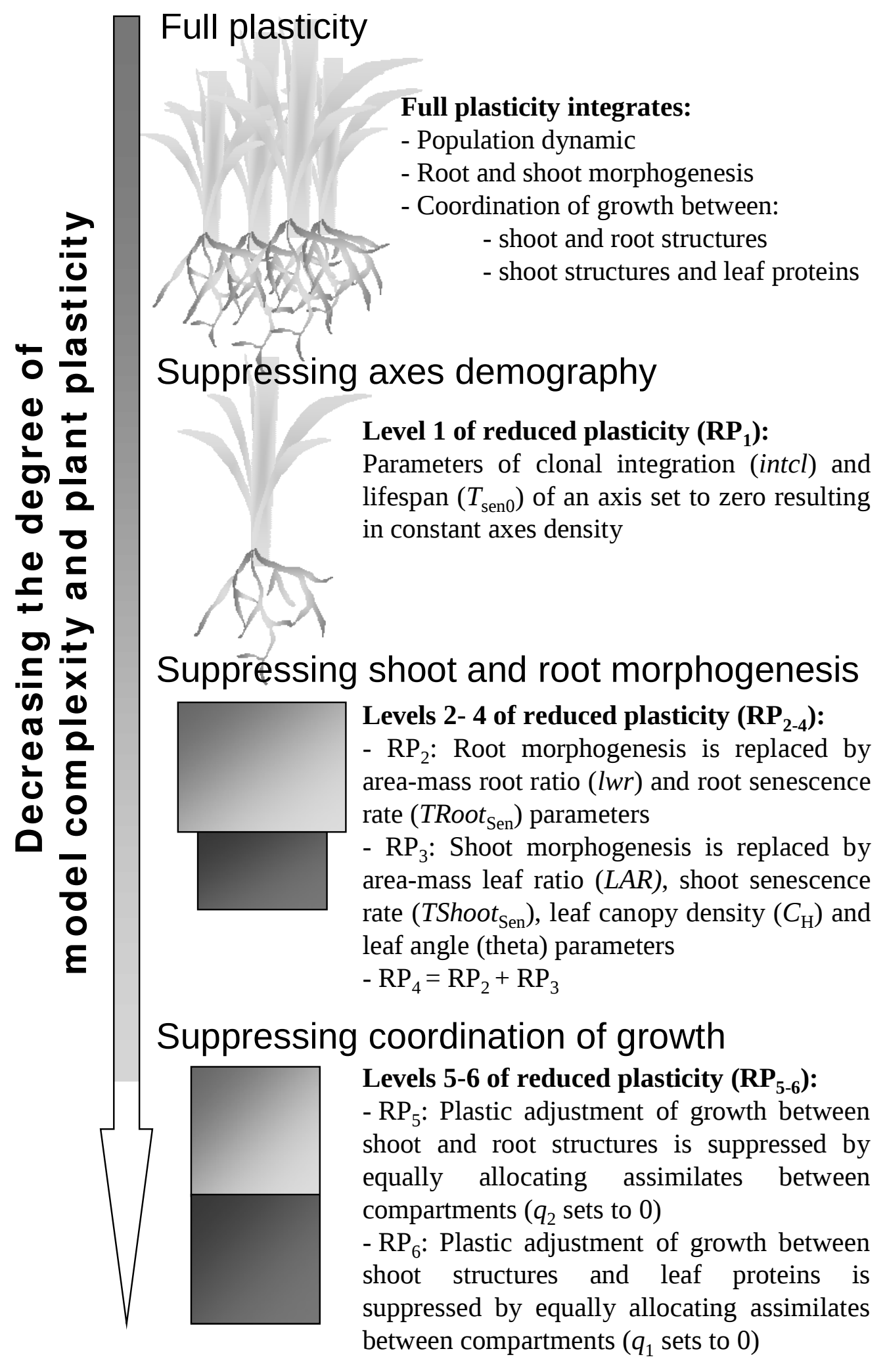

787Figure 1 



789Figure 2 


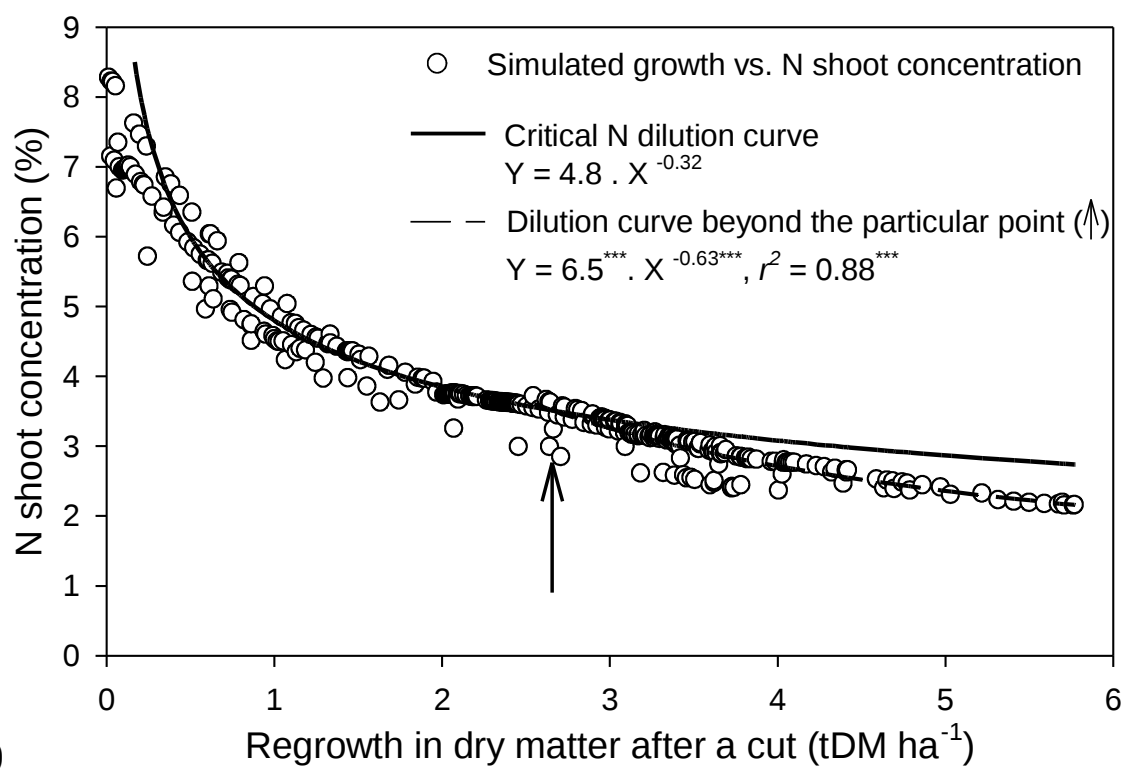

791Figure 3 

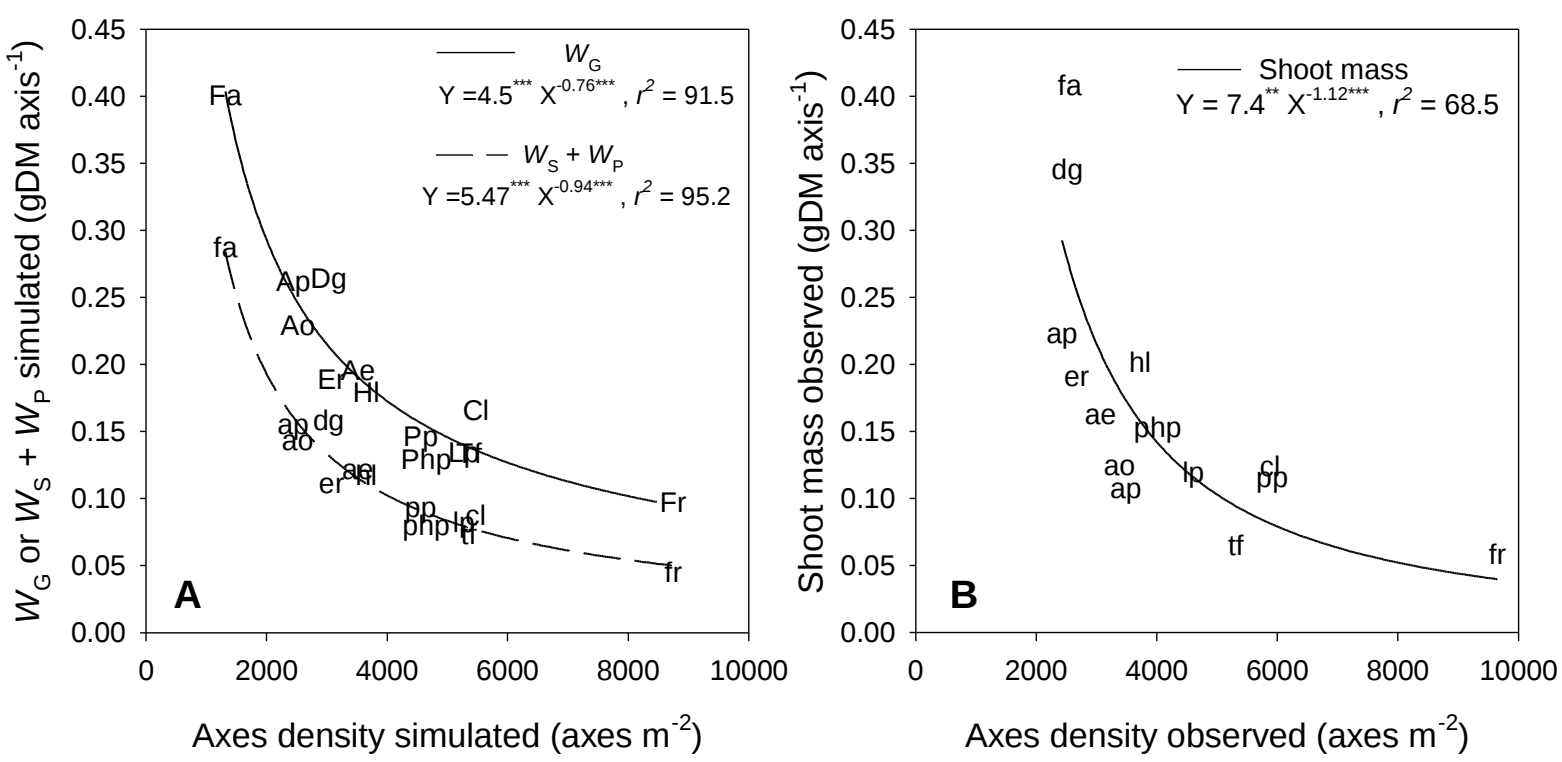

\section{Figure 4}




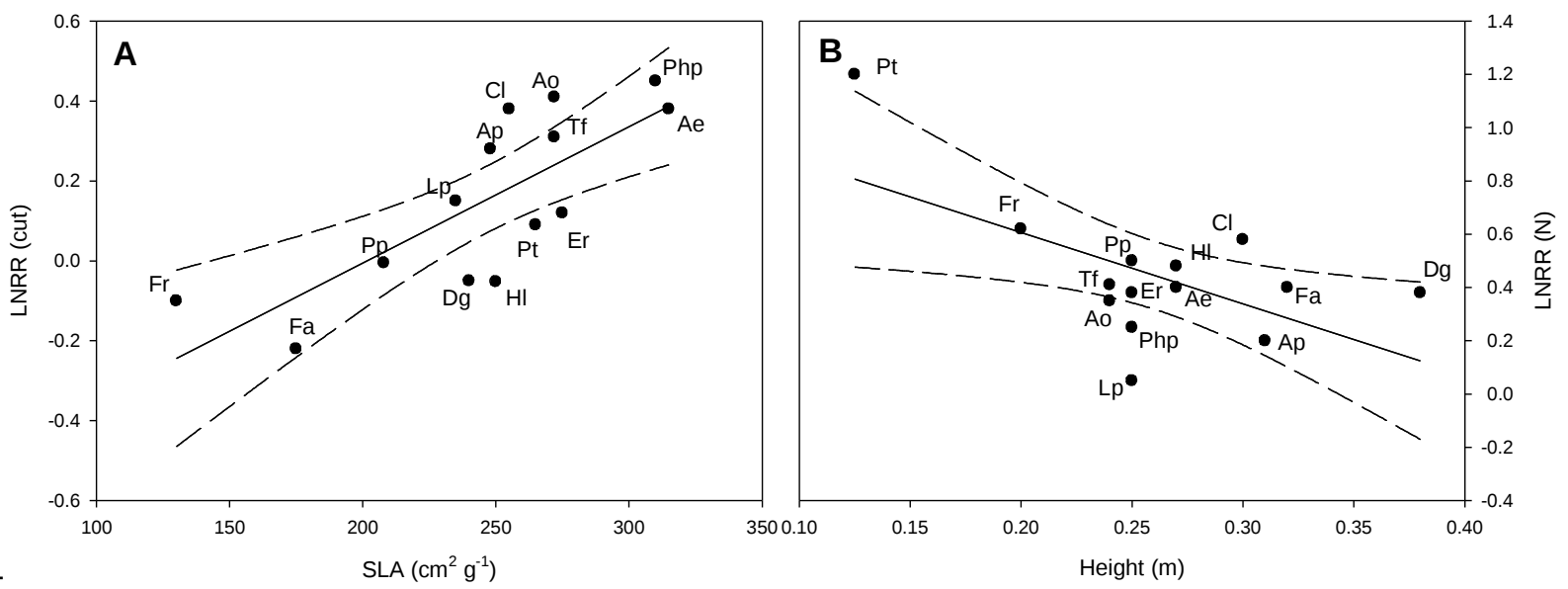

795Figure 5 


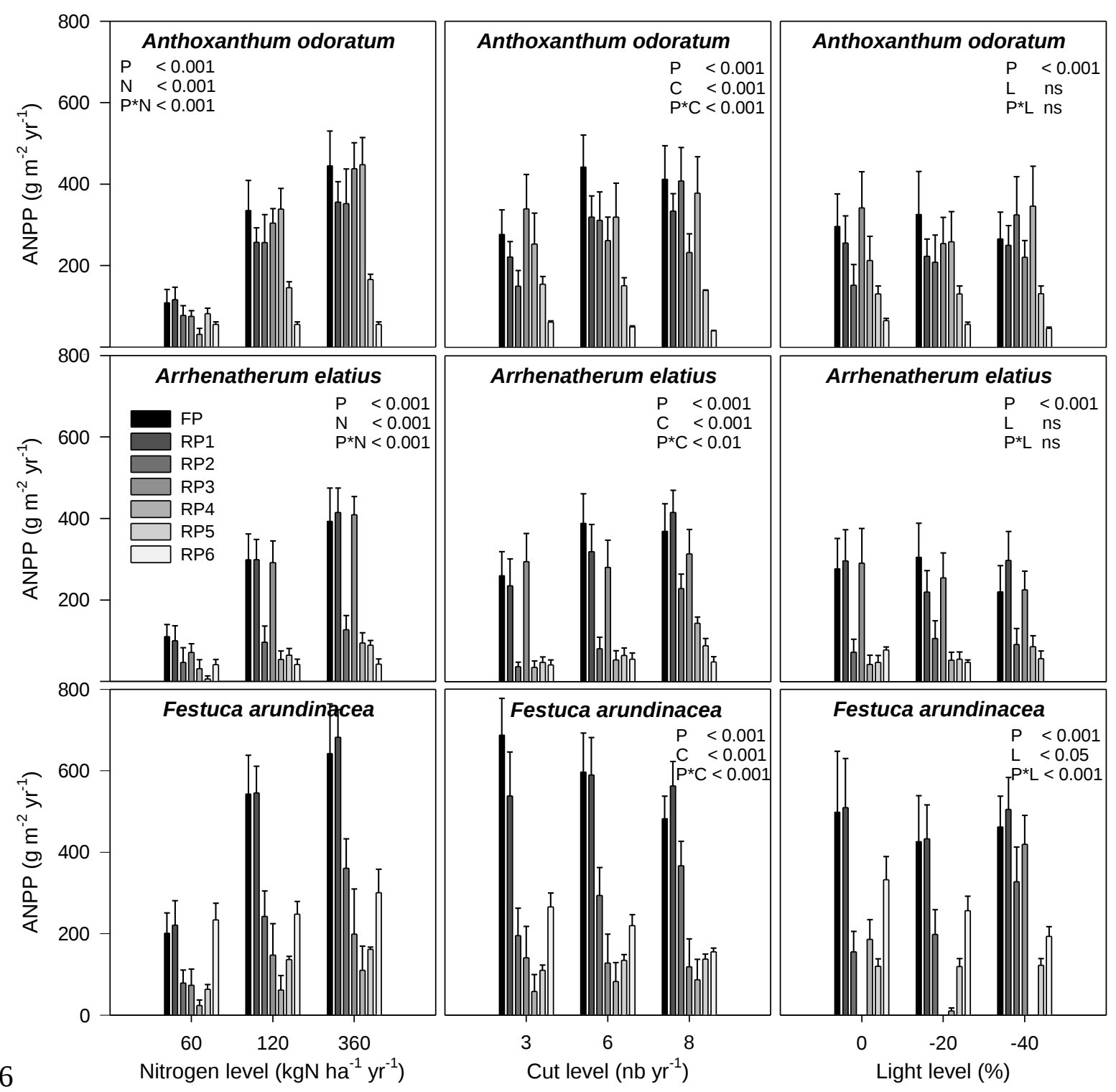

797Figure 6 


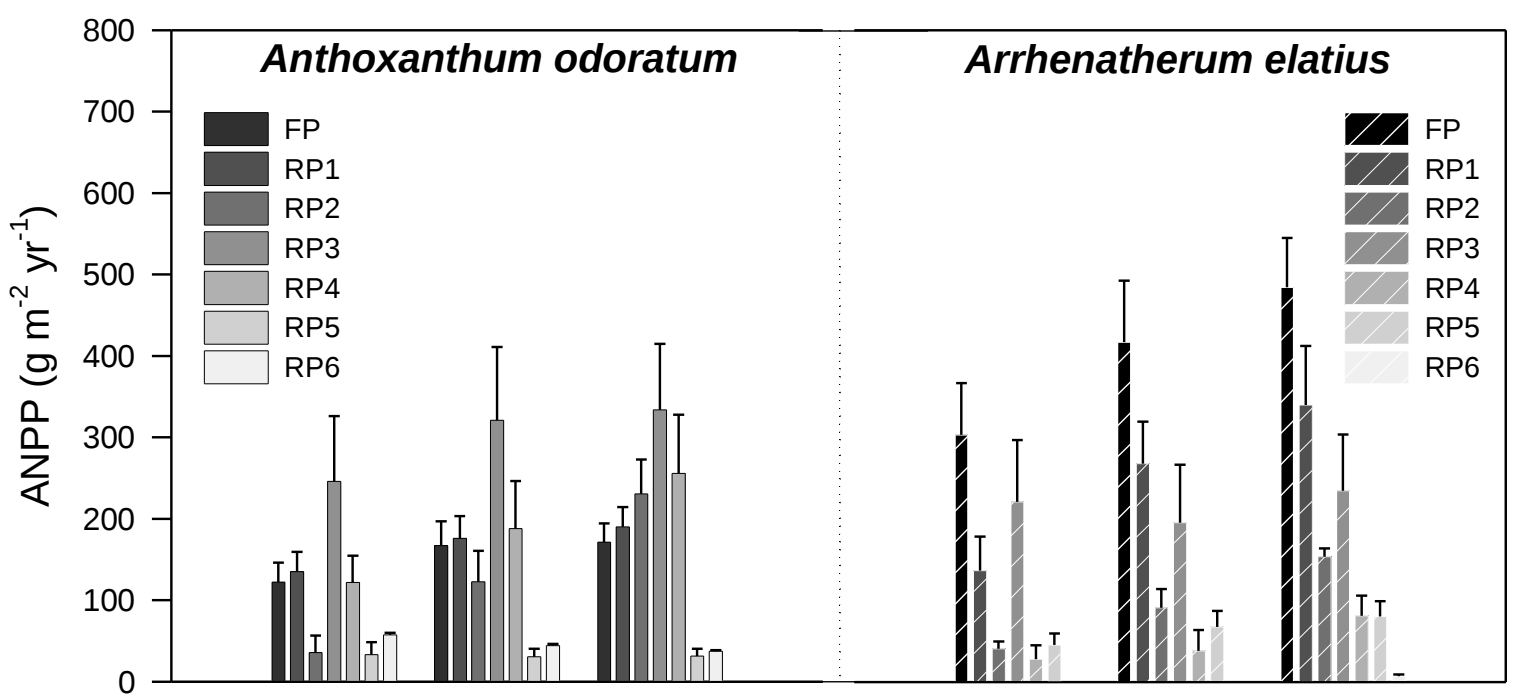

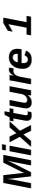
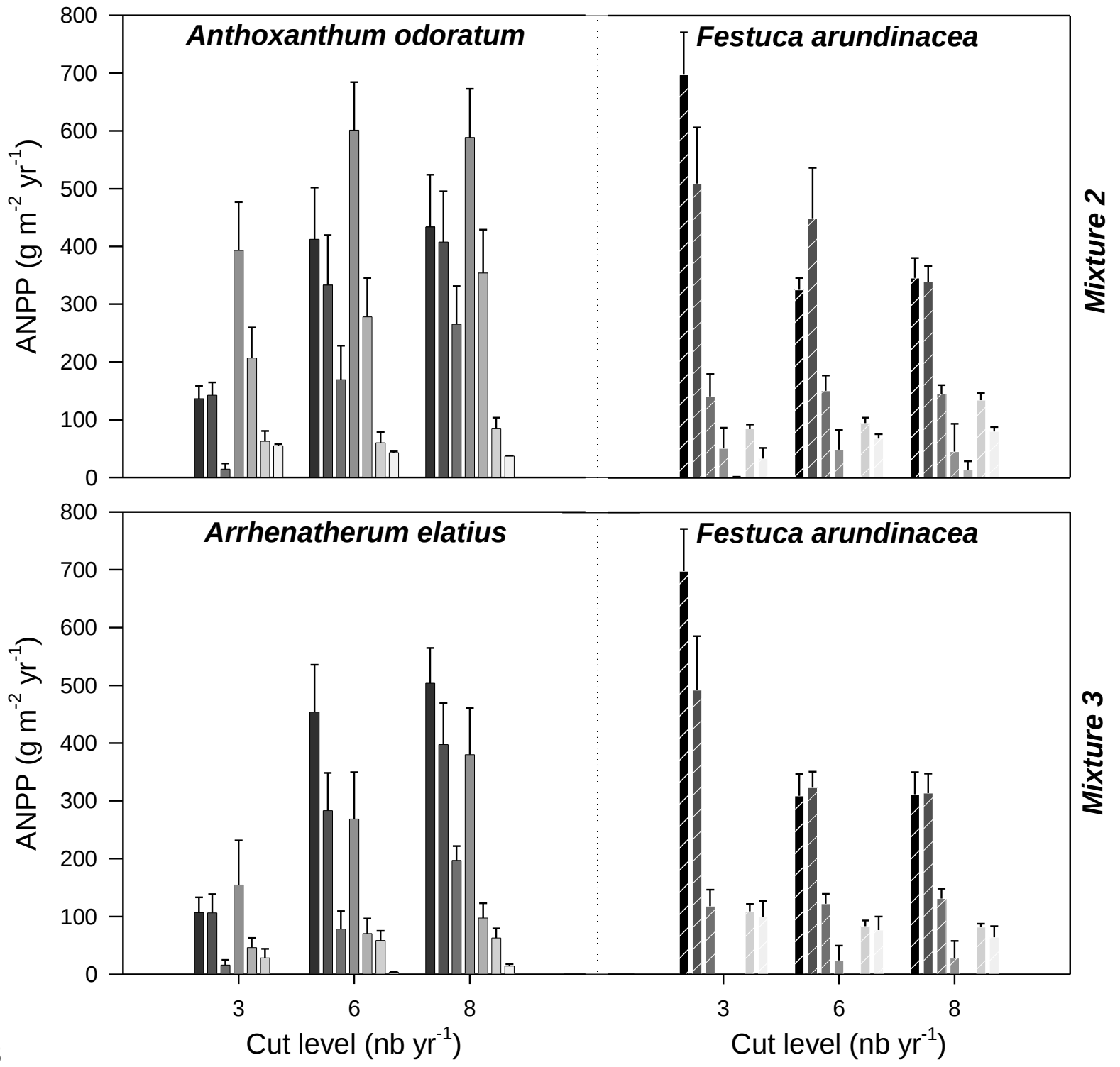

799 Figure 7. 


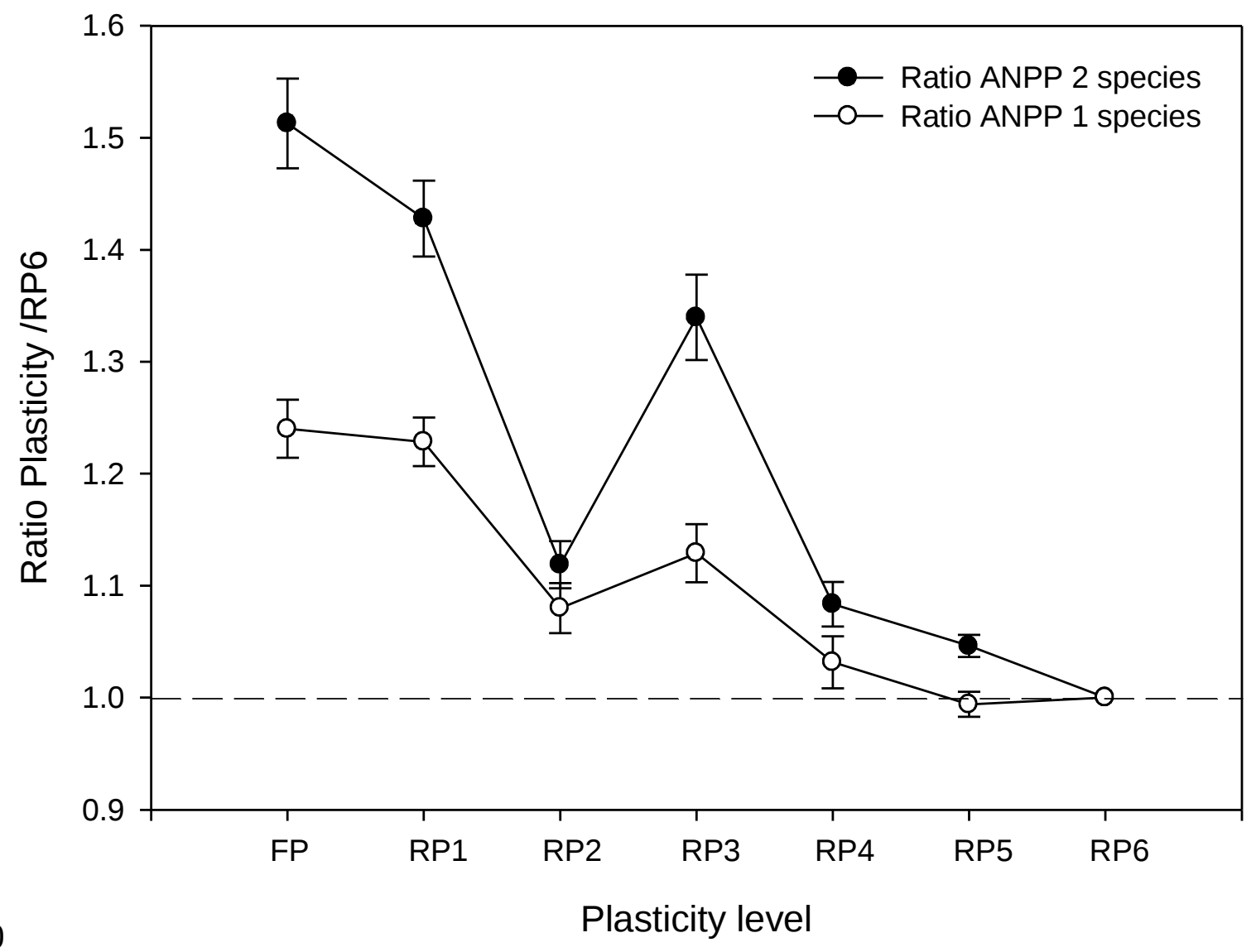

801Figure 8 